\title{
Estruturas invisíveis de segregação na Região Metropolitana de Goiânia
}

\author{
Ernesto Friedrich de Lima Amaral ${ }^{\star}$ \\ Camilo Vladimir de Lima Amaral ${ }^{\star \star}$
}

Este artigo visa investigar a estrutura invisível de segregação da Região Metropolitana de Goiânia (RMG), a partir das inter-relações entre processos de produção do espaço urbano, princípios de planejamento e dinâmicas populacionais. Essas inter-relações são fundamentais para compreender a estruturação de desigualdades socioeconômicas nas áreas metropolitanas. Realizou-se uma análise do processo de formação da estrutura de segregação na região, abordando os diversos planos urbanísticos desenvolvidos para Goiânia. Apresenta-se, ainda, uma breve análise de indicadores populacionais com base em dados dos Censos Demográficos de 1950 a 2010 e de indicadores locais de associação espacial em 2010, para caracterizar as diferentes dinâmicas da região. Foi desenvolvida uma análise crítica destes aspectos, a fim de identificar e exibir as principais características da formação desta região em um diagrama síntese. Procuramos discutir como esta estrutura espacial resultante contribui para a reprodução de relações sociais segregadas. Os principais resultados indicam que a RMG não possui uma simples centralidade ou uma pluricentralidade. Há uma série de anéis concêntricos com diferentes tipos de centralidade funcionando em um sistema integrado - mas não inclusivo de segregação. Identificamos também tópicos de pesquisas para investigar dinâmicas sociais, demográficas e econômicas que permitem aumentar o entendimento da formação espacial e de planejamento urbano dessa região.

Palavras-chave: Região Metropolitana de Goiânia. Espaço urbano. Segregação. Planejamento urbano. História. Demografia. Indicadores. Brasil.

\footnotetext{
* Texas A\&M University, College Station, Texas, Estados Unidos (amaral@tamu.edu; https://orcid.org/0000-0003-01867557).

** Universidade Federal de Goiás, Goiânia-GO, Brasil (camilovla@ufg.br; http://orcid.org/0000-0003-1760-839X).
} 


\section{Introdução}

A inter-relação entre planejamento, produção do espaço e dinâmica demográfica é fundamental para compreender a estruturação das desigualdades socioeconômicas nos municípios. Porém, o cruzamento destas questões demanda uma análise cuidadosa dos dados e de sua dinâmica ao longo do tempo, a fim de evitar leituras superficiais. 0 caso do município de Goiânia pode ser revelador destas interações.

A desigualdade socioeconômica em Goiânia tem sido evidenciada por uma série de relatórios da Organização das Nações Unidas (ONU) no decorrer dos anos. Em 2008, a ONU indicou que as cidades mais desiguais na América Latina e Caribe, dentre 19 cidades analisadas, eram Goiânia, Brasília, Belo Horizonte, Fortaleza, São Paulo e Bogotá (UN-HABITAT, 2008). Essas cidades apresentaram coeficientes de Gini acima de 0,60, o que é considerado extremamente alto, segundo os padrões internacionais. Em 2010, a ONU afirmou que Goiânia apresentava a maior desigualdade na América Latina e Caribe, com índice de Gini igual a 0,65 (referente a 2005), num total de 24 cidades analisadas na região (UN-HABITAT, 2010). Em 2016, a ONU apresentou o mesmo resultado de Goiânia com dados de 2005 (UN-HABITAT, 2016). Porém, Goiânia ficou atrás de Brasília e Curitiba, que tiveram Gini de 0,67 , num total de 32 cidades analisadas na América Latina e Caribe. Além destas, somente nove cidades da África do Sul tiveram índice de Gini superior ao de Goiânia, se consideradas todas as 155 cidades de 74 países presentes no relatório (UN-HABITAT, 2016).

Ao mesmo tempo, segundo dados do Instituto Brasileiro de Geografia e Estatística (IBGE) de 2010, ${ }^{1}$ Goiânia possuía 423.297 domicílios particulares ocupados, sendo que apenas $1.066(0,25 \%$ do total) estavam situados em sete aglomerados subnormais ("favelas"). Além disso, 92,97\% dos domicílios possuíam abastecimento de água via rede geral, $6,55 \%$ via poço ou nascente na propriedade e os demais tinham outras formas de abastecimento. Como seria possível Goiânia ser uma das cidades mais desiguais do mundo, apesar de possuir baixo percentual de aglomerados subnormais e de fornecer água tratada para a maioria de seus cidadãos? Que estruturas de segregação estão invisíveis a estes indicadores agregados?

Uma dificuldade é o fato de essas análises de indicadores agregados não permitirem abordar a complexidade das estruturas de desigualdade em um espaço urbano que é hoje metropolitano. A análise dessa região não deve se restringir aos limites de Goiânia, ignorando que hoje o município funciona de forma integrada com os municípios vizinhos. É importante analisar as variações entre setores censitários da Região Metropolitana de Goiânia (RMG). Além disso, não podemos nos delimitar à ideia de que apenas “favelas” são

\footnotetext{
${ }_{1}^{1}$ Tabela 3217 (Domicílios particulares permanentes e moradores em domicílios particulares permanentes, por situação do domicílio, segundo a forma de abastecimento de água, o destino do lixo e a existência de energia elétrica) e Tabela 3379 (Domicílios particulares ocupados e população residente em domicílios particulares ocupados, nos municípios com presença identificada de aglomerados subnormais, total e em aglomerados subnormais, e número de aglomerados subnormais) do Censo Demográfico de 2010, disponibilizadas pelo Instituto Brasileiro de Geografia e Estatística (IBGE) no Sistema IBGE de Recuperação Automática (Sidra).
} 
espaços de segregação, usando somente índices recentes para negar sua existência. Outro fator é que os relatórios da ONU não buscaram demonstrar como é a estrutura espacial de segregação no município, não realizaram uma análise histórica da produção do espaço e da evolução do planejamento de Goiânia e nem analisaram outros indicadores demográficos, já que estes não eram os objetivos dos estudos. Os relatórios apenas demonstraram que Goiânia é desigual, sem revelar como.

Nossa estratégia de pesquisa é buscar entender como a RMG estrutura sua desigualdade no espaço. Para isso, investiga-se de que forma medidas de planejamento urbano foram sedimentando diferentes camadas de segregação. Desenvolvemos essa análise com identificação de grupos de setores censitários que evidenciam como o processo de segregação socioeconômico está estruturado na região.

Importantes estudos foram realizados para outras regiões metropolitanas (RIBEIRO; RIBEIRO, 2018), mas não englobaram a RMG. Há trabalhos sobre desigualdades socioespaciais na RMG, utilizando dados censitários até 2000 (MOYSÉS, 2004, 2005). 0 presente estudo contribui para este debate ao: abordar a maneira como o planejamento urbano foi sedimentando diferentes camadas de segregação ao longo das décadas na região; atualizar e acrescentar indicadores sociais de 1950 até 2010; analisar dados espaciais e socioeconômicos agregados por setores censitários; e permitir a visualização de como a desigualdade em Goiânia foi produzida por meio de várias camadas históricas e de como está estruturada em uma escala que engloba as grandes distâncias da região metropolitana.

Goiânia surgiu como precursora para a interiorização do Brasil, já adiantando dinâmicas socioespaciais do que viria a ocorrer na transferência da capital nacional para o Planalto Central (CUNHA; BAENINGER, 1999). Esta dinâmica está sintetizada no Quadro A1 do Apêndice A. Até 1950, Goiânia cresceu e se desenvolveu sob um intenso controle do Estado (GRAEFF, 1985), buscando manter seu modelo “ideal” original. Isso gerou um crescimento populacional contínuo e lento em suas áreas oficiais, ao mesmo passo que outra cidade crescia em acampamentos na margem direita do Córrego Botafogo, em vilas rurais e loteamentos de chácaras. A década de 1950 viu uma crescente perda de controle do Estado, com uma ocupação do espaço espraiada e uma explosão populacional. Nos anos 1960, 1970 e 1980 renasceu a intervenção do Estado, associada com empreendedores imobiliários e focada na "produção do espaço" como "mercadoria” (HARVEY, 2005). Isso resultou uma “urbanização incompleta” (SANTOS, 1996) e um “espaço dividido” (SANTOS, 1979) entre a cidade planejada e a cidade das "invasões planejadas”. Este foi um fenômeno próprio de Goiânia, em que diferentes agentes (Estado, empreendedores imobiliários e posseiros urbanos) ocuparam e parcelaram a terra (ARANTES, 1992; CAMPOS; BERNARDES, 1991; CHAVES, 1985). A década de 1990 observou outro paradoxo: o incremento de um planejamento compreensivo na área central, somado à maior dinâmica populacional nas bordas. Houve uma reinvenção da produção do espaço segregado com o surgimento dos primeiros condomínios fechados. A partir de 2000, esse paradoxo se acentuou sobre o município, intensificando a implantação de condomínios fechados, o que reforçou as desigualdades 
de amenidades urbanas por meio de parcerias público-privadas e integrou Goiânia ainda mais com municípios do entorno.

Assim, a dinâmica do espaço metropolitano deve ser compreendida a partir destes conflitos entre o planejamento e seus esquecimentos (os lugares a ele invisíveis). É importante ainda abordar a dinâmica demográfica no espaço e o modo concreto de como as desigualdades se reproduzem em novas formatações. Esta perspectiva pode lançar nova luz sobre uma série de fenômenos: a especulação imobiliária; as distorções do planejamento; os conflitos de interesse; a dinâmica das pressões demográficas; as pressões sobre o ambiente natural; o espraiamento do tecido urbano; as conurbações urbanas; e a justiça espacial (SOJA, 2000). 0 quadro atual é ainda de uma urbanização incompleta, com grande diferenciação territorial quanto ao acesso a serviços urbanos (escolas, segurança, saúde, etc.), infraestrutura urbana (especialmente esgotamento sanitário) e qualidade ambiental (preservação da natureza, espaços públicos adequados, etc.).

No presente artigo buscamos analisar a RMG a partir de uma abordagem que integra discussão sobre a produção do espaço urbano e indicadores demográficos. Tal perspectiva visa melhor entender estruturas de segregação que podem ser “invisíveis" à população em geral e ao poder público em particular. Essa análise indica que há uma estrutura espacial de segregação “integrada e funcional” na RMG, mas isso não significa que ela é inclusiva. Diferentes padrões populacionais estão articulados espacialmente, estabelecendo relações espaciais entre eles, sem que isso signifique que o espaço resultante seja igualitário ou homogêneo. Com representação diagramática, foi possível delimitar estas diferenciações em padrões geométricos e revelar a formação de áreas segregadas e como elas se articulam, criando padrões lógicos e com funcionalidade analisável, apesar de invisíveis a olho nu. Neste artigo, analisaremos esta estrutura espacial de segregação integrada e não inclusiva da RMG.

A seguir, é realizada uma breve contextualização do planejamento e produção do espaço em Goiânia. Na seção seguinte, explicitam-se as estratégias de pesquisa e fontes de dados utilizadas. Posteriormente, são apresentados os resultados da análise, com o intuito de entender a dinâmica de segregação socioeconômica na RMG nas últimas décadas. Por fim, apontam-se algumas considerações sobre a aparente "invisibilidade" desta segregação e indica-se como este arcabouço abre novos tópicos de pesquisas sobre a dinâmica demográfica da região.

\section{Contextualização}

A história das cidades planejadas quase sempre se resume ao plano inicial, porque este assume a capacidade de traduzir, ainda que momentaneamente, o significado de circunstâncias específicas de uma ação programada sobre o espaço. Porém, uma análise crítica revela "campos cegos" dessa teoria, ou seja, aquilo que não é percebido e se desenvolve fora de sua utopia. Poderíamos dizer que se desenvolve como heterotopias (LEFEBVRE, 
1986, 1999). Para a RMG, a análise da integração entre o planejamento urbano, a dinâmica demográfica e a produção do espaço permite revelar como a cidade é resultado tanto do que foi programado para seu espaço, quanto do que foram as externalidades deste processo.

O plano original de Goiânia foi concebido por Attilio Corrêa Lima de 1933 a 1935. Sua proposta de modernização se baseava em uma cultura classicista, em que referências clássicas, como Versailles, propunham uma “cidade ideal” (painel A da Figura 1). 0 traçado de Goiânia caracteriza-se por ser radiocêntrico, tendo como ponto de convergência o centro administrativo, sede das Secretarias Estaduais, que se encontravam distribuídas ao redor de uma grande praça (a Praça Cívica), irradiando seu poder para o entorno.

FIGURA 1

Croquis de planos urbanísticos de Goiânia
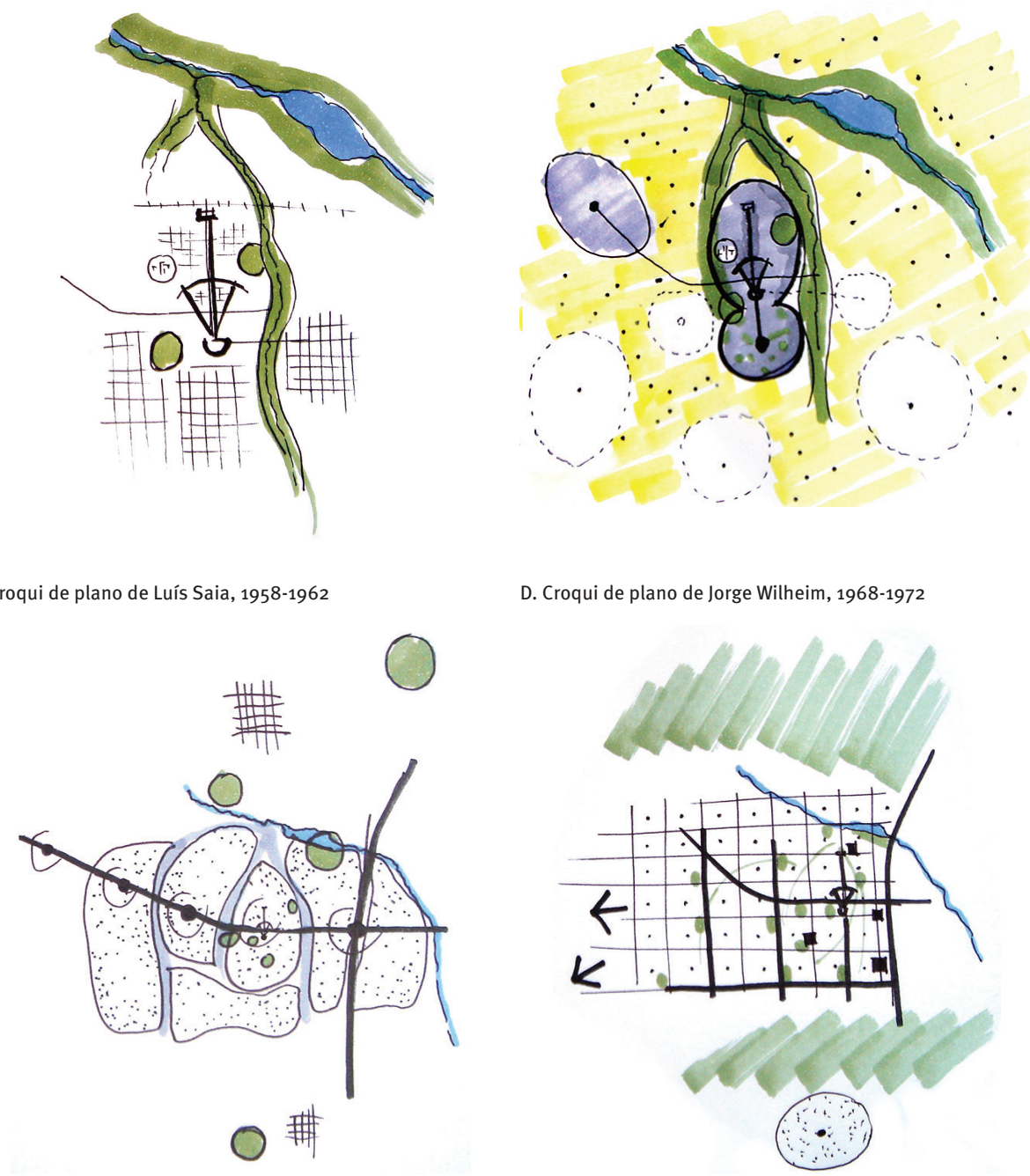
E. Croqui de plano desenvolvimento integrado de Goiânia da Engevix, 1992

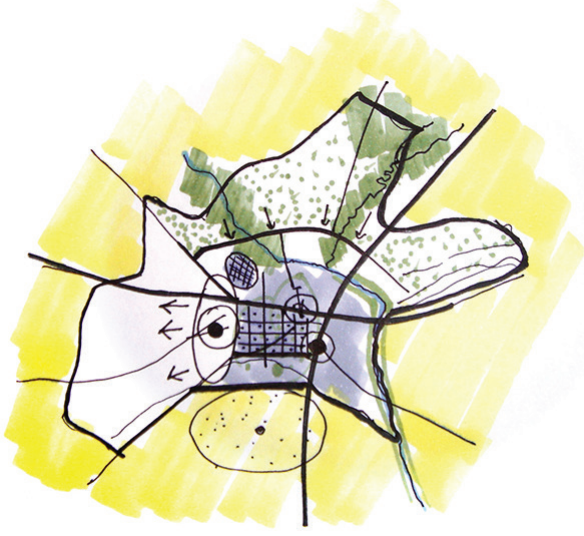

F. Croqui de plano diretor da Secretaria de Estado de Gestão e Planejamento (Seplan), 2006

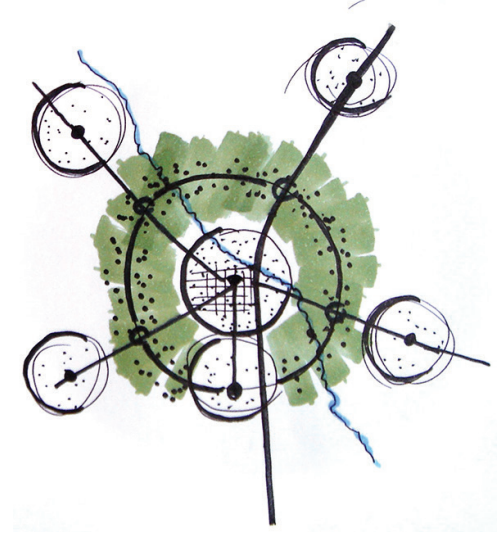

Fonte: Elaborado por Camilo Vladimir de Lima Amaral.

Corrêa Lima preocupava-se com a disciplina do trânsito e com um zoneamento eficiente (LIMA, 1942). Para isso, ele separou o centro político-administrativo do centro comercial. 0 primeiro ficou fora da movimentação densa, somente atraindo a circulação que estava diretamente destinada a ele. 0 centro empresarial foi planejado no cruzamento da Avenida Goiás (eixo norte-sul) com a Avenida Anhanguera (eixo leste-oeste). As atividades industriais se localizariam na região norte da cidade. Este zoneamento visava disciplinar o espaço.

Entre 1936 e 1938, o engenheiro Armando Augusto de Godoy assumiu a seção de urbanização de Goiânia. Godoy orientou a alteração de zoneamento da região central e modificou o desenho de alguns bairros. Ele sobrepôs a ideia de cidade-jardim às propostas iniciais, entrecruzando cidade e jardins, em que a natureza seria o percurso diário e o coração das relações comunitárias (GRAEFF, 1985). A cidade deveria crescer em pequenos núcleos urbanos, entremeados de áreas de campo e agricultura (painel B da Figura 1).

As propostas de Corrêa Lima e Godoy para o espaço da capital foram sendo assimiladas e reproduzidas por seus moradores, mas nem sempre com a mesma intenção do planejador. Surgiram diversas invasões, num processo de sobreposição entre espaços legais e ilegais da cidade (AMARAL, 2000). Este processo de invasão foi realizado com o consentimento do governador, que emitia cartas de autorização para a ocupação desses terrenos. Até hoje há reminiscências na malha urbana da sobreposição do espaço concebido idealmente (com traçado rígido e avenidas radiais) e o espaço produzido espontaneamente pela população (com formas orgânicas e ruas estreitas) (GONÇALVES, 2003).

Até meados dos anos 1940, o parcelamento da área urbana e a comercialização de lotes eram de competência exclusiva do Estado. Após esse período, a Associação Comercial pressionou o governo estadual pelo direito de lotear áreas que estavam sob seu controle. Um código de edificações foi elaborado, mas vigorou somente até 1950. A pressão imobiliária sobre Goiânia ampliou-se com a chegada da ferrovia em 1951, a política de interiorização 
do governo Getúlio Vargas, a inauguração da Usina Rochedo com fornecimento de energia elétrica, a pavimentação da Rodovia Goiânia-São Paulo, a implantação da Telegoiás e a criação das Universidades Federal e Católica. Posteriormente, houve aumento da especulação imobiliária em função da construção de Brasília, do fortalecimento da Usina Siderúrgica Nacional e do direcionamento da indústria automobilística e de bens de luxo para o Centro-Oeste.

Nesse contexto, um decreto municipal suprimiu a maioria das exigências de implantação de infraestrutura por parte dos empreendedores imobiliários. A maior parte do território da cidade foi parcelada. Grandes áreas vazias foram formadas, espraiando a ocupação. Apesar de abaixar o valor dos terrenos e ampliar o acesso da população, esta se encontra dispersa num vasto território onde o Estado não tem condições de instalar infraestrutura urbana. Surgiu um padrão de desigualdades que não é medido pela legalidade ou ilegalidade da ocupação, mas sim pela distância que se encontra da infraestrutura instalada (BONDUKI; ROLNIK, 1979).

Em 1959, a aprovação de novos loteamentos foi suspensa até que fosse realizada uma revisão geral dos loteamentos já aprovados. Com a extrapolação de todas as previsões de crescimento da cidade, o governo do Estado convidou o arquiteto paulista Luís Saia para elaborar um novo plano diretor para Goiânia. 0 plano de 1958-1962 se baseou numa nova forma de pensar a cidade (painel C da Figura 1). Buscou-se compreender a cidade dentro de sua característica regional, em que novos aspectos como a migração campo-cidade, o crescente processo de urbanização, o aumento da área urbana e a consequente conurbação passavam a ser temas do planejamento (OLIVEIRA, 1985; SAIA, 1962). Saia apresentou propostas para direcionar a ocupação do espaço, respeitando as características de cada lugar e aproveitando as suas potencialidades. 0 plano abandonou a proposta de expansão por cidades-jardim e adotou a ideia de cidade compacta. Haveria a formação de "polos" de atividades econômicas, além de redistribuição de serviços e equipamentos urbanos (OLIVEIRA, 1985).

O Censo Demográfico de 1960 indicou uma população de 153.505 habitantes em Goiânia, extrapolando a previsão do plano inicial de 50.000 habitantes. Diante do constatado e do previsto, Saia propôs algumas correções com os seguintes critérios: remoção das instalações obsoletas; complementação do arcabouço urbano com instalações novas; controle do uso do solo urbano com normas disciplinares; e instalações de módulos destinados a possibilitar a realização das obras oficiais. Para Saia, os planejamentos daquele momento trabalhavam com um horizonte de dez anos, que projetavam para a cidade uma população de 350.000 habitantes. Segundo o Censo de 1970, Goiânia alcançou 380.773 habitantes.

Com o golpe de 1964 e a deposição do governador Mauro Borges, este plano foi esquecido e pouco estudado. Nas décadas seguintes, houve um processo de intensa concentração dos espaços urbanos, em que Goiânia consolidou-se como polo de desenvolvimento regional. Foi o período em que a Prefeitura de Goiânia ganhou independência em relação 
ao governo estadual e se viu sob forte influência da administração federal. A cidade entrou na política federal de planos de desenvolvimento urbano para municípios de porte médio.

Entre 1968 e 1972, outro plano foi elaborado por Jorge Wilheim (painel D da Figura 1), que adotou uma concepção “desenvolvimentista”, buscando racionalizar e estruturar a cidade em uma modulação de $1 \mathrm{~km}$ por $1 \mathrm{~km}$, o que deveria redistribuir os serviços de forma homogênea. A malha viária existente foi alterada e hierarquizada em um "macrotraçado" ortogonal, visando integrar as regiões "atrasadas" aos núcleos desenvolvidos da cidade. Wilheim mudou o discurso do planejamento relacionado à modernização para um processo de desenvolvimento sustentado, visando a integração dos espaços atrasados na economia moderna.

A questão habitacional foi concebida como produção em "massa” de conjuntos habitacionais, coincidindo com as perspectivas do Banco Nacional da Habitação e da Empresa Brasileira de Transportes Urbanos. Estas perspectivas foram classificadas como "falso problema habitacional” (BOLAFFI, 1979), pois pressupunham a implantação de habitação por grandes empresas capitalistas e não por outros modelos mais comunitários e preocupados com as populações atendidas.

Em 1979, Nion Albernaz assumiu a prefeitura, anunciando que seu mandato seria orientado pelo planejamento (IPLAN, 1992). ${ }^{2}$ Porém, na região noroeste da cidade, iniciava-se a primeira invasão "planejada” de Goiânia por centenas de pessoas (MOYSÉS, 2004). Em busca de legitimação, o governo fez vistas grossas a este processo. Como consequência, essa região passou a ser produzida pela própria população, independentemente do governo (MOYSÉS; BERNARDES, 2005).

Somente após a abertura política, um novo plano diretor seria desenvolvido, sendo contratada a empresa Engevix para sua elaboração em 1992 (painel E da Figura 1). Algumas questões do "Movimento pela Reforma Urbana", inseridas na Constituição Federal de 1988, foram abordadas pontualmente. Este plano seguiu os princípios de uma "ciência urbana" já constituída, formulando um "plano compreensivo", que buscou tratar a cidade interdisciplinarmente. 0 plano, apresentado como solução global dos problemas urbanos, revisou todo o sistema administrativo, de fiscalização, gestão e regulação da cidade. Embora o plano tenha incluído em suas discussões as áreas de ocupação e a proteção ambiental da região norte, o processo de segregação e a dinâmica demográfica já eram substancialmente metropolitanos.

O Projeto Goiânia 21 - Operação Centro de 1998 nasceu em resposta ao processo de popularização pelo qual vinha passando o centro de Goiânia (ARANTES, 2015). Este projeto foi uma iniciativa que tentou resgatar os marcos e monumentos da cidade. 0 plano buscava evidenciar que o centro, área mais antiga de Goiânia, necessitava de mudanças

\footnotetext{
${ }^{2}$ Ele apresentou (75 dias após a eleição) as "Diretrizes" do Governo Municipal, que continham dez políticas para administrar a cidade, um programa de ação, 45 subprogramas e 217 projetos. Em seguida, foi contratado o arquiteto Lubomir Ficinsky, que elaborou as "Diretrizes Básicas para o Planejamento", com base no estudo do Indur: "Goiânia: uma Estratégia para Expansão Urbana". Poucos desses projetos se concretizaram, demonstrando a desvinculação entre o "discurso" dos planos e as ações práticas do prefeito (IPLAN, 1992).
} 
para resgatar seu papel na construção da identidade da cidade, respeitando o passado histórico e o ideário popular em relação à cidade. No entanto, não houve uma preocupação com uma visão totalizante da cidade. Os projetos limitavam-se à área central do plano ideal original, nos termos de seus arquitetos e não da experiência concreta de todos aqueles que viveram o processo.

Em 2006, um plano diretor da Secretaria de Estado de Gestão e Planejamento (Seplan) foi entregue à Câmara Municipal de Goiânia, focando dois critérios básicos: desenvolvimento sustentável e planejamento estratégico (painel F da Figura 1). A proposta para a área já urbanizada seguiu o modelo das cidades compactas, elaborado para a comunidade europeia. Nesta concepção, a área de expansão urbana é eliminada, devendo ser aumentado o índice construtivo da cidade, de tal forma que esta cresça sobre si mesma. 0 plano propõe revolucionar a organização da cidade, levando seu núcleo para um anel viário que circundaria toda a cidade, reforçando o seu caráter metropolitano. Ao longo deste novo centro disperso, seriam incentivadas atividades "sustentáveis" com baixo índice de ocupação e distribuindo serviços para toda a RMG. Porém, vetos na aprovação deste novo plano na Câmara Municipal, além do abandono de muitas das propostas aprovadas, impediram que a visão da questão metropolitana fosse de fato implementada.

Atualmente, um Plano de Desenvolvimento Integrado da Região Metropolitana de Goiânia está sendo produzido. Atrasos nos pagamentos e falta de perspectiva política para sua implementação ainda deixam incertezas se este plano será capaz de finalmente tratar a dinâmica espacial da região a partir de uma escala mais ampla. Esta contextualização permite iniciar a visualização de como a estrutura de segregação espacial da região vai se transformando historicamente em função das ideias e práticas de planejamento. Além disso, percebe-se a influência que as diferentes formas de produção do espaço tiveram nas dinâmicas demográficas da região. A seguir, apresentamos nossa estratégia de pesquisa para melhor entender a formação da estrutura espacial de segregação na RMG.

\section{Estratégia de pesquisa}

A análise sobre a formação do espaço urbano da RMG procura integrar história de formação da estrutura de segregação nessa região e investigação de indicadores demográficos. Na seção anterior, foi realizada uma análise histórica de planejamento urbano, procurando entender como o planejamento da cidade foi se transformando ao longo das décadas. Para isso, elaborou-se uma série de croquis que buscaram sintetizar essa discussão para um melhor entendimento da dinâmica de planos urbanísticos de Goiânia. Isso possibilitou o entendimento de como o planejamento urbano na RMG foi moldando diferencialmente espaços incluídos e excluídos, o que vai além de uma simples revisão da literatura.

Na próxima seção, é realizado um conjunto de três estudos que se complementam: visão geral histórica da evolução da população dos municípios da RMG; segregação espacial atual da RMG; e síntese da análise de produção do espaço urbano e da segregação espacial 
da RMG. Mais especificamente, apresentam-se dados censitários da RMG agregados por municípios de 1950 a 2010. Isso possibilita realizar um estudo geral de indicadores populacionais de forma histórica. Em seguida, são analisados dados censitários da RMG agregados por setores censitários de 2010. Nesse caso, o foco é entender os padrões atuais de segregação espacial, considerando pequenas áreas dentro da RMG e uma série de variáveis socioeconômicas, demográficas e de infraestrutura. Por fim, é feita uma análise interpretativa destes dados para gerar um diagrama síntese, o qual facilita o entendimento da estrutura espacial de segregação na RMG. Um detalhamento de cada uma destas três atividades é realizado a seguir.

Em primeiro lugar, empregaram-se dados dos Censos Demográficos coletados pelo IBGE para gerar uma série de indicadores demográficos de 1950, 1960, 1970, 1980, 1991, 2000 e 2010 dos municípios da RMG. Mais especificamente, são utilizados relatórios dos Censos Demográficos do Sistema IBGE de Recuperação Automática (Sidra): Tabela 202 (População residente, por sexo e situação do domicílio) e Tabela 1287 (População dos municípios das capitais e percentual da população dos municípios das capitais em relação aos das unidades da federação nos Censos Demográficos). Dados de tamanho populacional dos municípios por ano possibilitam gerar os seguintes indicadores:

- taxa de crescimento médio anual de cada município da RMG e da região como um todo;

- distribuição da população por tamanho populacional dos municípios, classificados em menos de 20.000 habitantes, 20.000 a 49.999 habitantes, 50.000 a 99.999 habitantes, 100.000 ou mais habitantes e município de Goiânia;

- incremento absoluto médio anual da RMG, do município de Goiânia e dos demais municípios da RMG, obtido pela subtração entre as populações no final e começo do período, posteriormente dividido pelo número de anos entre os Censos;

- participação do município de Goiânia e dos demais municípios da RMG no incremento absoluto médio anual da RMG. Por exemplo, o indicador do município de Goiânia é obtido pela divisão do incremento absoluto médio anual deste município pelo incremento da RMG;

- participação da RMG no incremento absoluto de Goiás e do Brasil. Por exemplo, este indicador é obtido pela subtração entre as populações no final e começo do período para a RMG e Goiás, posteriormente dividindo o valor da região metropolitana pelo valor de Goiás.

Posteriormente, foram utilizados dados agregados por setores censitários do Censo Demográfico de 2010 para fazer uma análise de agrupamentos espaciais das variáveis de rendimento médio domiciliar per capita, percentual de pessoas alfabetizadas e percentual de pessoas de cor/raça branca na RMG. Também estimaram-se, para cada setor censitário, percentual de domicílios com abastecimento da rede geral de água, percentual de domicílios com lixo coletado e percentual de domicílios com banheiro e esgotamento sanitário via rede geral de esgoto ou pluvial. No Apêndice A, encontram-se as variáveis dos resultados 
do universo do Censo Demográfico de 2010, agregados por setores censitários, que foram utilizadas para estimar cada um destes indicadores (Quadro A2). Este material possibilita entender exatamente quais variáveis foram utilizadas na análise, o que permite replicar os resultados, assim como desenvolver estudos semelhantes para outras áreas do país.

Elaborou-se uma série de mapas com as distribuições destes indicadores por setores censitários, que se encontram no Apêndice A (Figuras A1 e A2). Os indicadores de rendimento médio domiciliar per capita foram classificados por quantis (painel A da Figura A1). Para facilitar comparações entre os mapas, foram agregados por faixas percentuais similares $(0,0 \%$ a $20,0 \% ; 20,0 \%$ a $40,0 \% ; 40,0 \%$ a $60,0 \%, 60,0 \%$ a $80,0 \% ; 80,0 \%$ a $100,0 \%)$ os indicadores com percentuais de pessoas alfabetizadas (painel B da Figura A1), pessoas de cor/raça branca (painel $C$ da Figura $A 1$ ), domicílios com rede geral de água (painel $D$ da Figura A1), domicílios com lixo coletado (painel A da Figura A2) e domicílios com rede geral de esgoto (painel $B$ da Figura A2). Estes mapas permitem visualizar a maneira como os dados originais são disponibilizados para análise. Porém, eles não são essenciais para o entendimento dos resultados sobre indicadores locais de associação espacial. Os principais resultados com dados espaciais são apresentados em mapas na próxima seção.

Para cada um destes mapas no Apêndice A, estimamos a estatística I de Moran, que é um indicador de autocorrelação espacial global (ANSELIN, 2018). 0 índice é o resultado da comparação entre uma determinada variável espacial e sua correspondente variável espacial defasada. A variável defasada é o valor da característica investigada nas áreas vizinhas de cada uma das áreas em análise. A matriz de vizinhança foi estimada como sendo todos os setores censitários vizinhos a cada um dos setores ("contiguidade rainha"), utilizando contiguidade de primeira ordem (primeiros vizinhos de fronteira) (ANSELIN, 2018). 0 I de Moran testa a hipótese nula de aleatoriedade espacial global. Em nosso caso, este indicador testa se as pessoas ou domicílios com determinadas características estão distribuídos de forma aleatória nos setores censitários da RMG. Se pessoas e domicílios com certas características estão concentrados em determinados setores censitários, a hipótese nula de aleatoriedade espacial é rejeitada (ANSELIN, 2018; 2019).

Também foram estimados indicadores locais de associação espacial (LISA), para cada setor censitário da RMG, considerando cada uma das variáveis em análise, no sentido de detectar padrões locais de autocorrelação espacial. Tais indicadores são também chamados de I de Moran locais, incluindo também valores de seus vizinhos j (ANSELIN, 1995). Cada valor de LISA é avaliado no processo de estimação para verificar se é estatisticamente significativo (ANSELIN, 2019).

Os valores de LISA significativos são organizados em quatro agrupamentos (clusters). Este procedimento permite simplificar os mapas e melhor entender os grupos de setores censitários com características semelhantes. Com base no valor padronizado de uma variável em um determinado setor censitário e no valor padronizado de seus vizinhos, é possível classificar os indicadores locais em quatro grupos: "alto-alto", "baixo-baixo”, “baixo-alto" e "alto-baixo". Mais especificamente, há um grupo formado por setores censitários que 
apresentam valores altos para determinada variável e são circundados por setores com valores altos para a mesma variável ("alto-alto"). Há outro grupo de setores censitários com valores baixos, circundados por setores com valores baixos da mesma variável ("baixo-baixo"). Um terceiro grupo são os setores com valores baixos da variável, circundados por setores com valores altos ("baixo-alto"). Por fim, há um grupo de setores com valores altos circundados por setores com valores baixos ("alto-baixo"). Esses quatro grupos possuem significância estatística, ou seja, os valores da variável não estão distribuídos aleatoriamente no espaço. Os demais setores censitários identificados por essa análise não possuem significância estatística espacial para a variável em questão. Esse resultado também é informativo, já que delimita um conjunto de setores censitários que possuem valores altos, médios e baixos distribuídos aleatoriamente em uma determinada porção da RMG. Ou seja, são áreas com menor caráter de segregação espacial para a variável analisada.

Análises espaciais utilizando agrupamentos de LISA já foram realizadas para diversos temas e áreas do Brasil (AMARAL, 2011; CANCIAN; VIDIGAL; VIDIGAL, 2013; CHIARINI, 2008, 2009; CUNHA; JAKOB, 2010; MARCONATO et al., 2015; MENDONÇA; RAMOS; FRIAS, 2018; MENHEM; AMARAL, 2014; NUNES, 2013; PEROBELLI; HADDAD, 2006; RIGOTTI; VASCONCELLOS, 2005; SANTOS; CARVALHO; BARRETO, 2015, 2017; SILVA; SOUZA; MARTINS, 2012; SILVEIRA et al., 2010). Nossa intenção é usar essa ferramenta metodológica para investigar o processo de segregação espacial nos setores censitários da RMG, o que não foi realizado por estudos anteriores.

No presente trabalho, utilizou-se o programa computacional de análise espacial GeoDa para estimar o I de Moran, LISA, significância estatística e agrupamentos de LISA (ANSELIN, 2005,2018 , 2019). Posteriormente foi utilizado o programa computacional QGIS para melhor formatar os mapas apresentados neste artigo. Ambos programas computacionais são disponibilizados gratuitamente. Os setores censitários no município de Goiânia são territorialmente menores do que os dos outros municípios da região metropolitana. Na próxima seção, nos mapas com os dados espaciais, há somente os contornos dos municípios. Os contornos dos setores censitários não aparecem para facilitar a visualização dos resultados.

Selecionamos alguns mapas com agrupamentos de LISA para analisar na próxima seção (rendimento médio domiciliar per capita, percentual de pessoas alfabetizadas, percentual de pessoas de cor/raça branca e percentual de domicílios com rede geral de água). Estes mapas apresentam os principais resultados com dados espaciais e sintetizam de maneira clara a segregação socioeconômica, demográfica e de infraestrutura na RMG. Essa análise descritiva permite entender os resultados atuais do processo histórico de estruturação da segregação na RMG.

Por fim, elaborou-se o diagrama síntese da estrutura de segregação da RMG de maneira interpretativa, tal como foram realizados os croquis da Figura 1 que sintetizam o histórico de planejamento urbano da região. 0 novo diagrama não se baseia somente em informação sobre produção do espaço da região metropolitana. Sua especificidade é ser produzido a partir de uma interação entre o conhecimento que temos sobre o planejamento urbano da região (Figura 1) e a análise de segregação com dados censitários (apresentada 
a seguir). 0 diagrama síntese foi elaborado com as mesmas cores padrão dos mapas com agrupamentos de LISA, com o intuito de facilitar o entendimento da análise. Na próxima seção, detalham-se os resultados do estudo.

\section{Resultados}

Nesta seção são abordados indicadores da RMG agregados por municípios para descrever a composição populacional histórica da região de 1950 a 2010. Em seguida, apresentam-se mapas com informações socioeconômicas, demográficas e de infraestrutura pública agregados por setores censitários em 2010 para entender a segregação espacial atual na RMG. Também é realizada uma análise para integrar discussões de planejamento urbano da seção de contextualização com os indicadores aqui apresentados.

A RMG foi criada pela Assembleia Legislativa de Goiás, por meio da Lei Complementar n. 27, de 30 de dezembro de 1999. ${ }^{3}$ Naquele momento, a RMG era composta por 11 municípios: Goiânia, Abadia de Goiás, Aparecida de Goiânia, Aragoiânia, Goianápolis, Goianira, Hidrolândia, Nerópolis, Santo Antônio de Goiás, Senador Canedo e Trindade. A LC n. 48, de 9 de dezembro de 2004, incluiu Bela Vista de Goiás na RMG, ${ }^{4}$ a LC n. 54, de 23 de maio de 2005, adicionou o município de Guapó, ${ }^{5}$ e a LC n. 78, de 25 de março de 2010, acrescentou Bonfinópolis, Brazabrantes, Caldazinha, Caturaí, Inhumas, Nova Veneza e Terezópolis de Goiás, totalizando 20 municípios na RMG (Tabela 1 e Figura 2). ${ }^{6}$

A Tabela 1 apresenta também a população dos municípios que atualmente compõem a RMG. De 1950 a 2010, a população passou de 70.731 para 2.173.141 habitantes. Esse crescimento ocorreu de forma acentuada até o começo da década de 1980. Em Goiânia, a taxa de crescimento anual caiu de 6,54\%, em 1970/1980, para 1,77\%, em 2000/2010. É importante observar as taxas de Aparecida de Goiânia, que é o segundo maior município do Estado de Goiás, localizado ao sul de Goiânia. No período de 1970/1980, Aparecida de Goiânia cresceu 19,02\% ao ano, apresentando um decréscimo nessa taxa nas décadas seguintes, chegando a 3,08\% em 2000/2010.

\footnotetext{
3 Lei Complementar n. 27, de 30 de dezembro de 1999. Disponível em: 〈http://www.gabinetecivil.goias.gov.br/leis_ complementares/1999/lei_complementar_n27.htm>.

${ }^{4}$ Lei Complementar n. 48, de 9 de dezembro de 2004. Disponível em: 〈http://www.gabinetecivil.goias.gov.br/leis_ complementares/2004/lei_complementar_n48.htm>.

${ }^{5}$ Lei Complementar n. 54, de 23 de maio de 2005. Disponível em: 〈http://www.gabinetecivil.goias.gov.br/leis_ complementares/2005/lei_complementar_n54.htm〉.

${ }^{6}$ Lei Complementar n. 78, de 25 de março de 2010. Disponível em: 〈http://www.gabinetecivil.goias.gov.br/leis_ complementares/2010/lei_complementar_n78.htm>.
} 
TABELA 1

População e taxa de crescimento médio anual percentual (1) Região Metropolitana de Goiânia - 1950-2010

\begin{tabular}{|c|c|c|c|c|c|c|c|c|}
\hline Municípios & $\begin{array}{c}\text { Ano de } \\
\text { fundação }\end{array}$ & 1950 & $\begin{array}{c}1960 \\
(1950 / 60)\end{array}$ & $\begin{array}{c}1970 \\
(1960 / 70)\end{array}$ & $\begin{array}{c}1980 \\
(1970 / 80)\end{array}$ & $\begin{array}{c}1991 \\
(1980 / 91)\end{array}$ & $\begin{array}{c}2000 \\
(1991 / 00)\end{array}$ & $\begin{array}{c}2010 \\
(2000 / 10)\end{array}$ \\
\hline \multicolumn{9}{|c|}{ Desde 1999 na RMG } \\
\hline Goiânia & 1933 & 53.389 & $\begin{array}{r}153.505 \\
(11,14)\end{array}$ & $\begin{array}{r}380.773 \\
(9,51)\end{array}$ & $\begin{array}{r}717.519 \\
(6,54)\end{array}$ & $\begin{array}{r}922.222 \\
(2,31)\end{array}$ & $\begin{array}{r}1.093 .007 \\
(1,91)\end{array}$ & $\begin{array}{r}1.302 .001 \\
(1,77)\end{array}$ \\
\hline $\begin{array}{l}\text { Abadia de } \\
\text { Goiás (2) }\end{array}$ & 1995 & & & & & & 4.971 & $\begin{array}{r}6.876 \\
(3,30)\end{array}$ \\
\hline $\begin{array}{l}\text { Aparecida de } \\
\text { Goiânia }\end{array}$ & 1922 & $\ldots(4)$ & $\ldots(4)$ & 7.470 & $\begin{array}{l}42.627 \\
(19,02)\end{array}$ & $\begin{array}{r}178.483 \\
(13,90)\end{array}$ & $\begin{array}{r}336.392 \\
(7,30)\end{array}$ & $\begin{array}{r}455.657 \\
(3,08)\end{array}$ \\
\hline Aragoiânia & 1958 & & $\ldots(4)$ & 2.848 & $\begin{array}{r}3.707 \\
(2,67)\end{array}$ & $\begin{array}{l}4.910 \\
(2,59)\end{array}$ & $\begin{array}{l}6.424 \\
(3,03)\end{array}$ & $\begin{array}{l}8.365 \\
(2,68)\end{array}$ \\
\hline Goianápolis (3) & 1958 & & $\ldots(4)$ & 7.340 & $\begin{array}{r}7.569 \\
(0,31)\end{array}$ & $\begin{array}{r}10.716 \\
(3,21)\end{array}$ & $\begin{array}{l}10.671 \\
(-0,05)\end{array}$ & $\begin{array}{r}10.695 \\
(0,02)\end{array}$ \\
\hline Goianira & 1922 & & 5.036 & $\begin{array}{l}6.091 \\
(1,92)\end{array}$ & $\begin{array}{r}7.488 \\
(2,09)\end{array}$ & $\begin{array}{r}12.896 \\
(5,07)\end{array}$ & $\begin{array}{r}18.719 \\
(4,23)\end{array}$ & $\begin{array}{r}34.060 \\
(6,17)\end{array}$ \\
\hline Hidrolândia & 1948 & $\ldots$ (4) & $\ldots(4)$ & 8.014 & $\begin{array}{l}8.559 \\
(0,66)\end{array}$ & $\begin{array}{r}10.254 \\
(1,66)\end{array}$ & $\begin{array}{r}13.086 \\
(2,75)\end{array}$ & $\begin{array}{r}17.398 \\
(2,89)\end{array}$ \\
\hline Nerópolis & 1948 & $\ldots(4)$ & 6.529 & $\begin{array}{l}7.735 \\
(1,71)\end{array}$ & $\begin{array}{l}9.368 \\
(1,93)\end{array}$ & $\begin{array}{r}12.987 \\
(3,01)\end{array}$ & $\begin{array}{r}18.578 \\
(4,06)\end{array}$ & $\begin{array}{r}24.210 \\
(2,68)\end{array}$ \\
\hline $\begin{array}{l}\text { Santo Antônio } \\
\text { de Goiás }\end{array}$ & 1993 & & & & & & 3.106 & $\begin{array}{l}4.703 \\
(4,24)\end{array}$ \\
\hline $\begin{array}{l}\text { Senador } \\
\text { Canedo }\end{array}$ & 1989 & & & & & 23.905 & $\begin{array}{r}53.105 \\
(9,27)\end{array}$ & $\begin{array}{r}84.443 \\
(4,75)\end{array}$ \\
\hline Trindade & 1920 & 17.342 & $\begin{array}{r}16.549 \\
(-0,47) \\
\end{array}$ & $\begin{array}{r}22.519 \\
(3,13) \\
\end{array}$ & $\begin{array}{r}30.609 \\
(3,12) \\
\end{array}$ & $\begin{array}{r}54.072 \\
(5,31) \\
\end{array}$ & $\begin{array}{r}81.457 \\
(4,66) \\
\end{array}$ & $\begin{array}{r}104.488 \\
(2,52) \\
\end{array}$ \\
\hline \multicolumn{9}{|c|}{ Desde 2004 na RMG } \\
\hline $\begin{array}{l}\text { Bela Vista de } \\
\text { Goiás }\end{array}$ & 1896 & $\ldots(4)$ & $\ldots(4)$ & 14.298 & $\begin{array}{r}17.255 \\
(1,90) \\
\end{array}$ & $\begin{array}{l}17.316 \\
(0,03) \\
\end{array}$ & $\begin{array}{r}19.210 \\
(1,16) \\
\end{array}$ & $\begin{array}{r}24.554 \\
(2,48) \\
\end{array}$ \\
\hline \multicolumn{9}{|c|}{ Desde 2005 na RMG } \\
\hline Guapó & 1948 & $\ldots$ (4) & $\ldots(4)$ & 8.804 & $\begin{array}{r}10.028 \\
(1,31) \\
\end{array}$ & $\begin{array}{r}11.785 \\
(1,48) \\
\end{array}$ & $\begin{array}{r}13.863 \\
(1,82) \\
\end{array}$ & $\begin{array}{r}13.976 \\
(0,08) \\
\end{array}$ \\
\hline \multicolumn{9}{|c|}{ Desde 2010 na RMG } \\
\hline Bonfinópolis & 1989 & & & & & 3.324 & $\begin{array}{l}5.353 \\
(5,44)\end{array}$ & $\begin{array}{r}7.536 \\
(3,48)\end{array}$ \\
\hline Brazabrantes & 1958 & & $\ldots(4)$ & 3.132 & $\begin{array}{r}2.241 \\
(-3,29)\end{array}$ & $\begin{array}{l}2.334 \\
(0,37)\end{array}$ & $\begin{array}{r}2.772 \\
(1,93)\end{array}$ & $\begin{array}{l}3.232 \\
(1,55)\end{array}$ \\
\hline Caldazinha & 1993 & & & & & & 2.859 & $\begin{array}{l}3.325 \\
(1,52)\end{array}$ \\
\hline Caturaí & 1953 & & $\ldots(4)$ & 4.669 & $\begin{array}{r}3.899 \\
(-1,79)\end{array}$ & $\begin{array}{l}4.134 \\
(0,53)\end{array}$ & $\begin{array}{l}4.330 \\
(0,52)\end{array}$ & $\begin{array}{l}4.686 \\
(0,79)\end{array}$ \\
\hline Inhumas & 1886 & $\ldots(4)$ & $\ldots(4)$ & 30.144 & $\begin{array}{r}31.430 \\
(0,42)\end{array}$ & $\begin{array}{r}38.368 \\
(1,83)\end{array}$ & $\begin{array}{r}43.897 \\
(1,51)\end{array}$ & $\begin{array}{r}48.246 \\
(0,95)\end{array}$ \\
\hline Nova Veneza & 1958 & & $\ldots(4)$ & 5.733 & $\begin{array}{r}5.083 \\
(-1,20)\end{array}$ & $\begin{array}{r}5.003 \\
(-0,14)\end{array}$ & $\begin{array}{r}6.414 \\
(2,80)\end{array}$ & $\begin{array}{r}8.129 \\
(2,40)\end{array}$ \\
\hline $\begin{array}{l}\text { Terezópolis de } \\
\text { Goiás }\end{array}$ & 1993 & & & & & & 5.083 & $\begin{array}{r}6.561 \\
(2,59) \\
\end{array}$ \\
\hline Total & & 70.731 & $\begin{array}{r}181.619 \\
(9,89)\end{array}$ & $\begin{array}{r}509.570 \\
(10,87)\end{array}$ & $\begin{array}{r}897.382 \\
(5,82)\end{array}$ & $\begin{array}{r}1.312 .709 \\
(3,52)\end{array}$ & $\begin{array}{r}1.743 .297 \\
(3,20)\end{array}$ & $\begin{array}{r}2.173 .141 \\
(2,23)\end{array}$ \\
\hline
\end{tabular}

Fonte: Relatórios dos Censos Demográficos do Estado de Goiás de 1950, 1960, 1970, 1980, 1991, 2000 e 2010 , publicados pelo IBGE. Sidra/IBGE, Tabela 202 (População residente, por sexo e situação do domicílio) e Tabela 1287 (População dos municípios das capitais e percentual da população dos municípios das capitais em relação aos das unidades da federação nos Censos Demográficos).

(1) A taxa de crescimento médio anual percentual é apresentada entre parênteses, abaixo do tamanho populacional, referente ao período entre os Censos da presente coluna e da coluna anterior.

(2) 0 município de Abadia de Goiás foi criado a partir de Goiânia, Trindade, Aragoiânia e Guapó.

(3) Após 1991, o município de Goianápolis foi dividido, originando Terezópolis de Goiás.

(4) Dados não disponibilizados pelo Instituto Brasileiro de Geografia e Estatística (IBGE) no Sistema IBGE de Recuperação Automática (Sidra). 
FIGURA 2

Alterações na composição dos municípios da Região Metropolitana de Goiânia (RMG) - 1999-2010

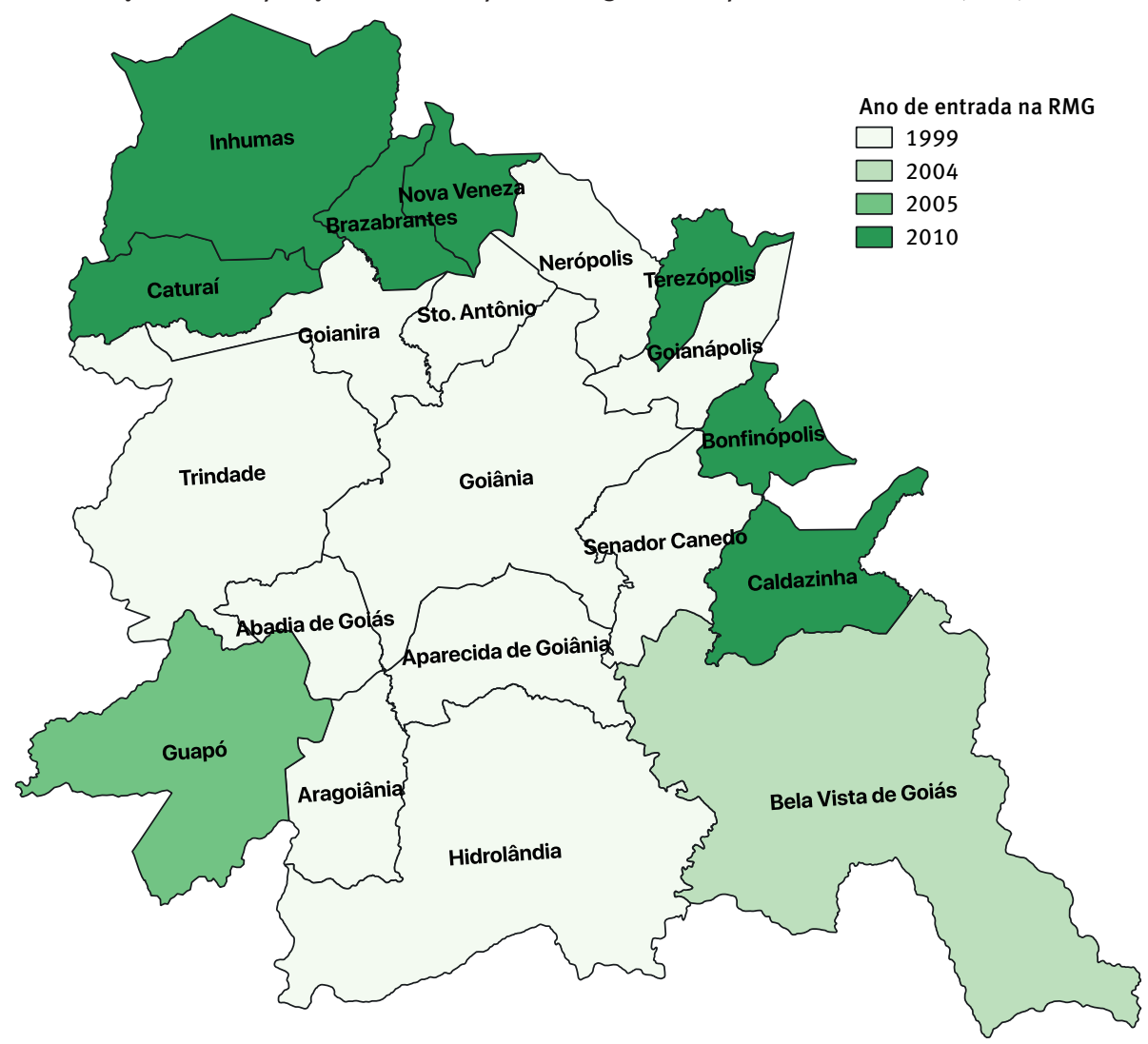

Fonte: Elaborado com base nas Leis Complementares n. 27, de 30 de dezembro de 1999, n. 48, de 9 de dezembro de 2004, n. 54, de 23 de maio de 2005 , e n. 78 , de 25 de março de 2010.

Na Tabela 2, os dados populacionais foram agrupados por tamanho dos municípios: menos de 20.000 habitantes; 20.000 a 49.999 habitantes; 50.000 a 99.999 habitantes; 100.000 ou mais habitantes; e município de Goiânia. Entre 1991 e 2010, os municípios metropolitanos de 20.000 a 49.999 habitantes e aqueles com mais de 100.000 habitantes apresentaram aumento em sua participação relativa no total absoluto da região. 0 município de Goiânia diminuiu sua participação relativa de $75,48 \%$ para 59,91\%, entre 1950 e 2010. Conforme dados da Tabela 1, é importante ressaltar que alguns municípios mudaram de categoria de tamanho populacional no período analisado. Por exemplo, Senador Canedo passou do grupo de municípios entre 20.000 e 49.999 habitantes em 1991 (23.905 habitantes) para o de 50.000 a 99.999 habitantes em 2000 (53.105 habitantes). Em razão disso, esse último grupo de municípios quase dobrou sua participação no total da RMG, passando de 4,12\% para 7,72\%, entre 1991 e 2000 . Outro exemplo é o município de Trindade, o qual passou da categoria de 50.000 a 99.999 habitantes em 2000 (81.457 habitantes) para a de 100.000 ou mais (104.488 habitantes) em 2010. Com 
isso, a participação relativa dos municípios de 50.000 a 99.999 habitantes caiu de $7,72 \%$ para 3,89\%, nesse mesmo período.

TABELA 2

Distribuição da população, por tamanho populacional dos municípios, e indicadores demográficos de crescimento

Região Metropolitana de Goiânia - 1950-2010

\begin{tabular}{|c|c|c|c|c|c|c|c|}
\hline $\begin{array}{l}\text { População e } \\
\text { indicadores }\end{array}$ & 1950 & 1960 & 1970 & 1980 & 1991 & 2000 & 2010 \\
\hline \multicolumn{8}{|l|}{$\begin{array}{l}\text { População por tamanho } \\
\text { do município (\%) }\end{array}$} \\
\hline Menos de 20.000 hab. & 24,52 & 15,48 & 14,94 & 8,38 & 7,29 & 7,77 & 4,39 \\
\hline 20.000 a 49.999 hab. & & & 10,33 & 11,66 & 4,74 & 2,52 & 6,03 \\
\hline 50.000 a 99.999 hab. & & & & & 4,12 & 7,72 & 3,89 \\
\hline 100.000 hab. ou mais & & & & & 13,60 & 19,30 & 25,78 \\
\hline Município de Goiânia & 75,48 & 84,52 & 74,72 & 79,96 & 70,25 & 62,70 & 59,91 \\
\hline Total & 100,00 & 100,00 & 100,00 & 100,00 & 100,00 & 100,00 & 100,00 \\
\hline \multicolumn{8}{|l|}{ População absoluta } \\
\hline RMG & 70.731 & 181.619 & 509.570 & 897.382 & 1.312 .709 & 1.743 .297 & 2.173 .141 \\
\hline Município de Goiânia & 53.389 & 153.505 & 380.773 & 717.519 & 922.222 & 1.093 .007 & 1.302 .001 \\
\hline $\begin{array}{l}\text { Demais municípios da } \\
\text { RMG }\end{array}$ & 17.342 & 28.114 & 128.797 & 179.863 & 390.487 & 650.290 & 871.140 \\
\hline Goiás & 1.214 .921 & 1.917 .460 & 2.938 .029 & 3.860 .174 & 4.018 .903 & 5.003 .228 & 6.003 .788 \\
\hline Brasil & 51.944 .397 & 70.070 .457 & 93.134 .846 & 119.011 .052 & 146.825 .475 & 169.799 .170 & 190.755 .799 \\
\hline Indicadores & & $1950 / 60$ & $1960 / 70$ & $1970 / 80$ & $1980 / 91$ & $1991 / 00$ & $2000 / 10$ \\
\hline \multicolumn{8}{|l|}{$\begin{array}{l}\text { Taxa de crescimento } \\
\text { médio anual (\%) }\end{array}$} \\
\hline RMG & & 9,89 & 10,87 & 5,82 & 3,52 & 3,20 & 2,23 \\
\hline Município de Goiânia & & 11,14 & 9,51 & 6,54 & 2,31 & 1,91 & 1,77 \\
\hline $\begin{array}{l}\text { Demais municípios da } \\
\text { RMG }\end{array}$ & & 4,95 & 16,44 & 3,40 & 7,30 & 5,83 & 2,97 \\
\hline \multicolumn{8}{|l|}{$\begin{array}{l}\text { Incremento absoluto } \\
\text { médio anual }\end{array}$} \\
\hline RMG & & 11.089 & 32.795 & 38.781 & 37.757 & 47.843 & 42.984 \\
\hline Município de Goiânia & & 10.012 & 22.727 & 33.675 & 18.609 & 18.976 & 20.899 \\
\hline $\begin{array}{l}\text { Demais municípios da } \\
\text { RMG }\end{array}$ & & 1.077 & 10.068 & 5.107 & 19.148 & 28.867 & 22.085 \\
\hline
\end{tabular}

Participação no incremento absoluto médio anual da RMG (\%)

Município de Goiânia

Demais municípios da RMG

$\begin{array}{llllll}90,29 & 69,30 & 86,83 & 49,29 & 39,66 & 48,62\end{array}$

$\begin{array}{llllll}9,71 & 30,70 & 13,17 & 50,71 & 60,34 & 51,38\end{array}$

\section{Participação da}

RMG no incremento absoluto (\%)

\begin{tabular}{lrrrrrr} 
De Goiás & 15,78 & 32,13 & 42,06 & 261,66 & 43,74 & 42,96 \\
Do Brasil & 0,61 & 1,42 & 1,50 & 1,49 & 1,87 & 2,05 \\
\hline
\end{tabular}

Fonte: Relatórios dos Censos Demográficos do Estado de Goiás de 1950, 1960, 1970, 1980, 1991, 2000 e 2010, publicados pelo IBGE. Sidra/IBGE, Tabela 202 (População residente, por sexo e situação do domicílio) e Tabela 1287 (População dos municípios das capitais e percentual da população dos municípios das capitais em relação aos das unidades da federação nos Censos Demográficos). 
A Tabela 2 apresenta também indicadores de crescimento e incremento populacional estimados com base na população da RMG, município de Goiânia, demais municípios da RMG, Goiás e Brasil de 1950 a 2010. As taxas de crescimento médio anual de Goiânia foram inferiores às dos demais municípios da RMG de maneira consistente desde 1980/1991. Estes resultados estão associados ao menor incremento absoluto médio anual de Goiânia, em relação aos demais municípios da região, no mesmo período. Mais especificamente, observa-se que o incremento absoluto médio anual de Goiânia diminuiu de 33.675 pessoas, em 1970/1980, para 18.609 pessoas, em 1980/1991, e se manteve estável nas décadas seguintes: 18.976 pessoas (1991/2000) e 20.899 pessoas (2000/2010). Enquanto isso, o incremento absoluto médio anual dos demais municípios da RMG apresentou um aumento considerável de 5.107 pessoas em 1970/1980, chegando ao valor máximo de 28.867 em 1991/2000 e continuando acima do município de Goiânia em 2000/2010 (22.085 pessoas). Estes dados ressaltam que está havendo uma maior procura por municípios da RMG fora da capital estadual.

A participação de Goiânia e dos demais municípios da RMG no incremento absoluto médio anual da população da RMG também pode ser analisada na Tabela 2. Observa-se que a tendência é de aumento das taxas dos demais municípios, com consequente queda da participação de Goiânia. No período 1950/1960, Goiânia respondia por 90,3\% do incremento absoluto médio anual da população da RMG, diminuindo para somente $39,7 \%$, em 1991/2000, e aumentando para 48,6\% no último período (2000/2010). Essa constatação atesta que a RMG está passando por um período de desconcentração urbana, com o deslocamento populacional de Goiânia para os demais municípios.

Pode-se ainda perceber que a RMG tem grande importância no crescimento da população de Goiás, já que participa em mais de 40,0\% no incremento absoluto dessa população desde 1970/1980 (Tabela 2). De 1980 a 1991, a população de Goiás aumentou de 3.860.174 para 4.018.903 habitantes (158.729 pessoas). No mesmo período, a população da RMG cresceu de 897.382 para 1.312.709 habitantes (415.327 pessoas). Isso explica o dado na Tabela 2 de que a RMG participou em 261,7\% (415.327/158.729*100) no incremento absoluto de Goiás. Este resultado evidencia que houve grande migração intraestadual de outros municípios goianos para a RMG. Porém, essa participação da RMG no incremento absoluto de Goiás decresceu nas últimas décadas, principalmente após 1991. Isso pode ser um indicativo de que outros polos de atração podem estar surgindo no Estado, direcionando os fluxos populacionais para essas regiões, como é o caso da microrregião do Entorno de Brasília. Além disso, a RMG apresentou aumento de participação no incremento absoluto do Brasil de 0,6\%, em 1950, para 2,1\%, em 2010.

A Figura 3 ilustra os índices I de Moran e os agrupamentos de LISA de variáveis socioeconômicas, demográficas e de infraestrutura nos setores censitários da RMG. Os índices I de Moran indicam uma autocorrelação espacial global positiva para os indicadores analisados. Todos índices foram estatisticamente significativos com pseudo $p$-valores iguais a 0,001. Estes resultados sugerem que setores censitários com altos níveis de um determinado 
indicador tendem a ser circundados por outros setores com altos níveis e vice-versa. Essa observação global do I de Moran para toda a RMG pode ser mais bem entendida para análises locais de cada setor censitário com os agrupamentos de LISA. Os mapas ilustram que os setores censitários com níveis mais altos de rendimento médio domiciliar per capita (painel A da Figura 3), percentual de pessoas alfabetizadas (painel B da Figura 3), percentual de pessoas de cor/raça branca (painel C da Figura 3) e percentual de domicílios com rede geral de água (painel D da Figura 3) se situam em setores censitários centrais do município de Goiânia, circundados por outros setores com as mesmas características (áreas em vermelho). Os municípios de Brazabrantes (norte da RMG), Caldazinha e Bela Vista de Goiás (sudeste da RMG) também apresentam alta concentração de pessoas de cor/raça branca. Os setores censitários com níveis menores dos indicadores apresentados na Figura 3 e que são circundados por outros setores com níveis menores (áreas em azul escuro) localizam-se em municípios vizinhos a Goiânia, principalmente ao norte.

No caso específico de percentuais de domicílios com rede geral de água (painel D da Figura 3), há uma maior quantidade de setores censitários na RMG com concentração de níveis menores deste indicador (áreas em azul escuro em volta do município de Goiânia), quando comparados aos outros indicadores. Isso ocorre justamente porque muitos domicílios de municípios vizinhos de Goiânia se localizam longe de centros urbanos ou em bairros que não possuem rede geral de água. No Apêndice $A$, também é possível analisar o mapa com agrupamentos de LISA para domicílios com rede geral de esgoto (painel D da Figura A2), o qual apresenta as mesmas configurações de rede geral de água (painel D da Figura 3). Os resultados de domicílios com lixo coletado (painel C da Figura A2) possuem menos setores censitários com níveis altos desse serviço na área central da RMG (menos áreas em vermelho).

Estes dados revelam que a estrutura de segregação urbana em Goiânia ultrapassa os limites do seu território. Percebe-se um alto contraste entre o município de Goiânia e o seu entorno. Inicialmente, podemos afirmar que a RMG se caracteriza por uma região central altamente concentrada e com indicadores positivos (áreas em vermelho). Em seguida, há um primeiro anel de setores censitários que rodeiam esta área e apresentam índices com níveis variados, ou seja, áreas com menor segregação (áreas em branco). Há um segundo anel mais largo que circunda toda a região com baixos índices de rendimento, alfabetização e rede geral de água (áreas em azul escuro). Por fim, há um terceiro anel com níveis variados de rendimento, principalmente no sul e sudeste da região (áreas em branco).

O segundo anel é formado, em grande parte, por área rural. Isso significa que a primeira característica para a segregação na RMG é o caráter de sua ocupação espacial. Neste segundo anel, orbitam algumas áreas, em sua maioria associadas a pequenos municípios, que possuem índices com níveis variados, o que reforça o argumento de que o espaço urbano é menos segregado nos "centros periféricos", ou seja, nos centros dos municípios menores. Este também é um indicativo de que há uma maior conexão dessas áreas com o município central (Goiânia), por serem mais bem servidas pelo sistema de transporte e infraestrutura 
viária. Outros exemplos destes "centros periféricos" são áreas que apresentam maiores níveis de rendimento, percentuais de pessoas alfabetizadas e percentuais de pessoas de cor/raça branca, circundadas por áreas com baixos percentuais (áreas em rosa). Além disso, aparecem dois "centros periféricos", um pequeno em Santo Antônio de Goiás (ao norte de Goiânia) e outro grande em Hidrolândia (ao sul de Goiânia), caracterizados por áreas com altos rendimentos cercadas por áreas com baixos rendimentos (áreas em rosa). Este elevado contraste social pode ser o resultado, por exemplo, da existência de condomínios fechados em Hidrolândia.

FIGURA 3

Agrupamentos de indicadores locais de associação espacial (LISA) de variáveis socioeconômicas, demográficas e de infraestrutura nos setores censitários

Região Metropolitana de Goiânia - 2010

A. Rendimento médio domiciliar per capita I de Moran: 0,7340 (pseudo p-valor: 0,001)
B. Percentual de pessoas alfabetizadas I de Moran: 0,4833 (pseudo p-valor: o,001)
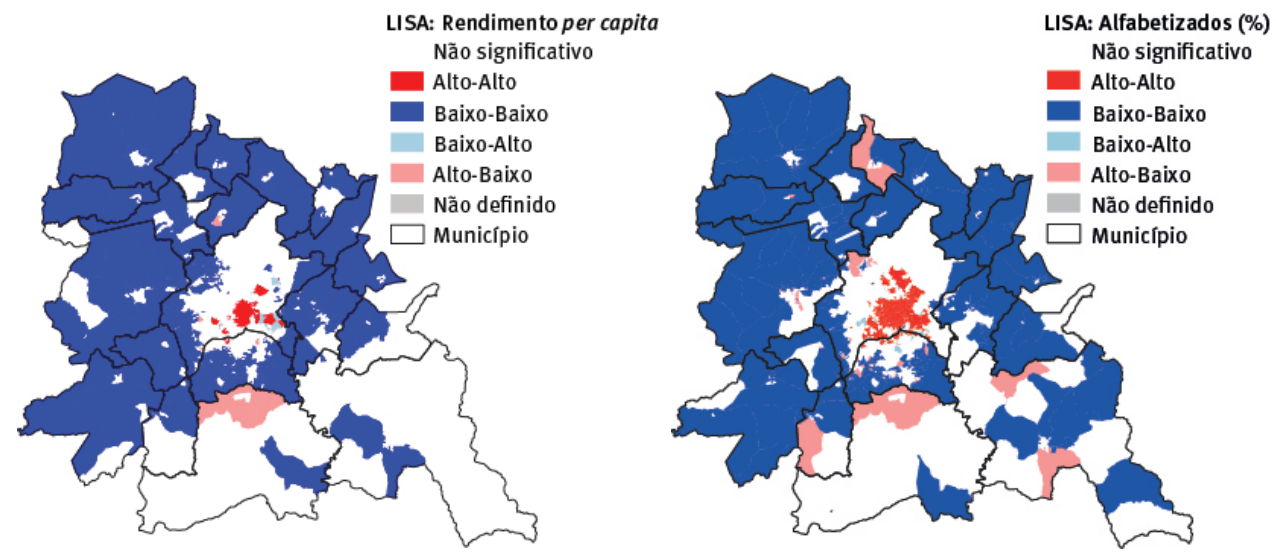

C. Percentual de pessoas de cor/raça branca I de Moran: o,6155 (pseudo p-valor: 0,001)

D. Percentual de domicílios com rede geral de água I de Moran: o,6611 (pseudo p-valor: 0,001)

LISA: Brancos (\%)

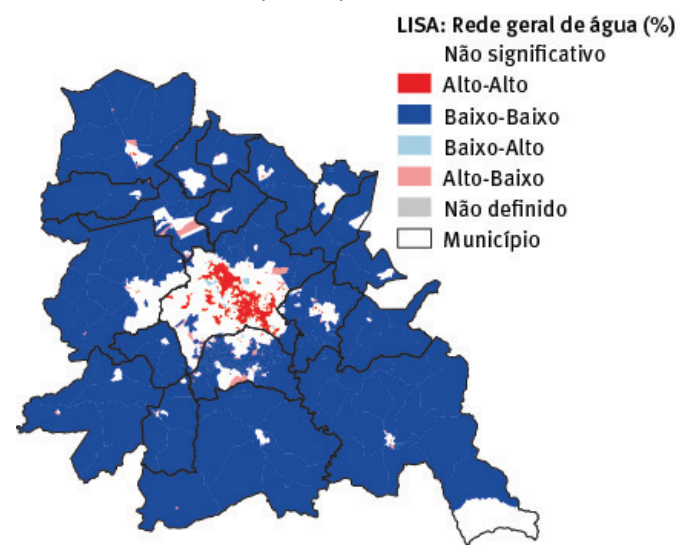

Fonte: Censo Demográfico do Brasil de 2010. 
Ainda em relação à variável de rendimento (Painel A da Figura 3), setores censitários centrais em Goiânia (áreas em vermelho) são orbitados por outras pequenas áreas em vermelho: os condomínios fechados, que se mantêm dentro da esfera do primeiro anel, o qual apresenta níveis variados quanto à renda (áreas em branco no Painel A da Figura 3) e altos percentuais quanto à alfabetização (áreas em vermelho no Painel B da Figura 3). De certa forma, isso configura uma vizinhança no entorno dos condomínios fechados formada por uma população com níveis variados de rendimento e com melhor escolaridade, o que pode indicar a formação de uma espécie de escudo social invisível, pois cria um entorno de "normalidade", impedindo sujeitos de visualizarem a alta segregação criada por estes condomínios. Desse modo, os condomínios orbitam as áreas centrais de Goiânia, absorvendo serviços e benefícios desta área sem comprometer sua importância. Em torno destas áreas orbitantes (condomínios fechados), há outros grupos de setores censitários de baixo rendimento. Isso pode ser entendido pelo fato de condomínios fechados demandarem muitos serviços com baixa remuneração (serventes domésticos, jardineiros, etc.). Há a formação de uma segregação integrada e funcional, sem ser inclusiva, já que, apesar destas últimas áreas servirem aos condomínios, elas não têm acesso aos seus benefícios espaciais.

Uma grande área no sudeste da RMG apresenta índices LISA sem significância estatística quanto ao percentual de pessoas alfabetizadas (áreas em branco no painel B da Figura 3). Neste mesmo sudeste, há algumas áreas com altos percentuais de pessoas de cor/raça branca, circundadas por áreas com altos percentuais de pessoas de cor/raça branca (áreas em vermelho no painel C da Figura 3). Nestas áreas, há indicativos de que não existe segregação significativa em relação a rendimentos (áreas em branco no painel A da Figura 3). Isso pode ser entendido pelo fato de estas áreas possuírem estrutura fundiária formada por propriedades menores de agricultura familiar, estarem associadas a algumas indústrias alimentícias e formarem um circuito produtivo próprio em relação à área central. Além disso, os maiores percentuais de pessoas de cor/raça branca podem ajudar a entender uma maior inclusão socioeconômica nestas áreas. Assim, observa-se a formação de um anel diferenciado, em que há uma pausa na estrutura espacial de segregação "integrada e funcional” da RMG, ou seja, uma exceção que contrasta com a regra encontrada nas outras áreas.

A Figura 4 busca sintetizar os mapas de agrupamentos de LISA (Figura 3) com o mesmo processo interpretativo utilizado para gerar os croquis relativos ao planejamento urbano da RMG (Figura 1), representando o funcionamento da estrutura espacial de segregação integrada e não inclusiva da RMG. 0 processo de formação do espaço urbano gera um sistema complexo de inter-relações metropolitanas:

- áreas ricas (círculos vermelhos) se localizam predominantemente dentro de um espaço equilibrado, o qual possui níveis variados de rendimento, ou seja, tem menor nível de segregação (primeiro anel em cinza); 
- essas áreas ricas são formadas por uma região central e orbitadas por outros satélites (círculos vermelhos), incluindo dois mais externos (em Santo Antônio de Goiás ao norte e Hidrolândia ao sul);

- observam-se áreas de pobreza no nordeste e leste do primeiro anel (círculos azuis dentro do primeiro anel em cinza), que formam satélites de pobreza em torno de centros de riqueza;

- há uma grande área geográfica de áreas pobres (segundo anel em azul), distantes da área central, formando um pano de fundo para a região;

- há os "centros periféricos” que são outras áreas distantes e soltas neste pano de fundo (círculos cinzas dentro do segundo anel em azul);

- há áreas com níveis variados de rendimento ainda mais afastadas da região central, principalmente no sul e sudeste (terceiro anel em cinza);

- há áreas de pobreza no sudeste (círculos azuis dentro do terceiro anel em cinza).

FIGURA 4

Diagrama síntese da estrutura de segregação da Região Metropolitana de Goiânia
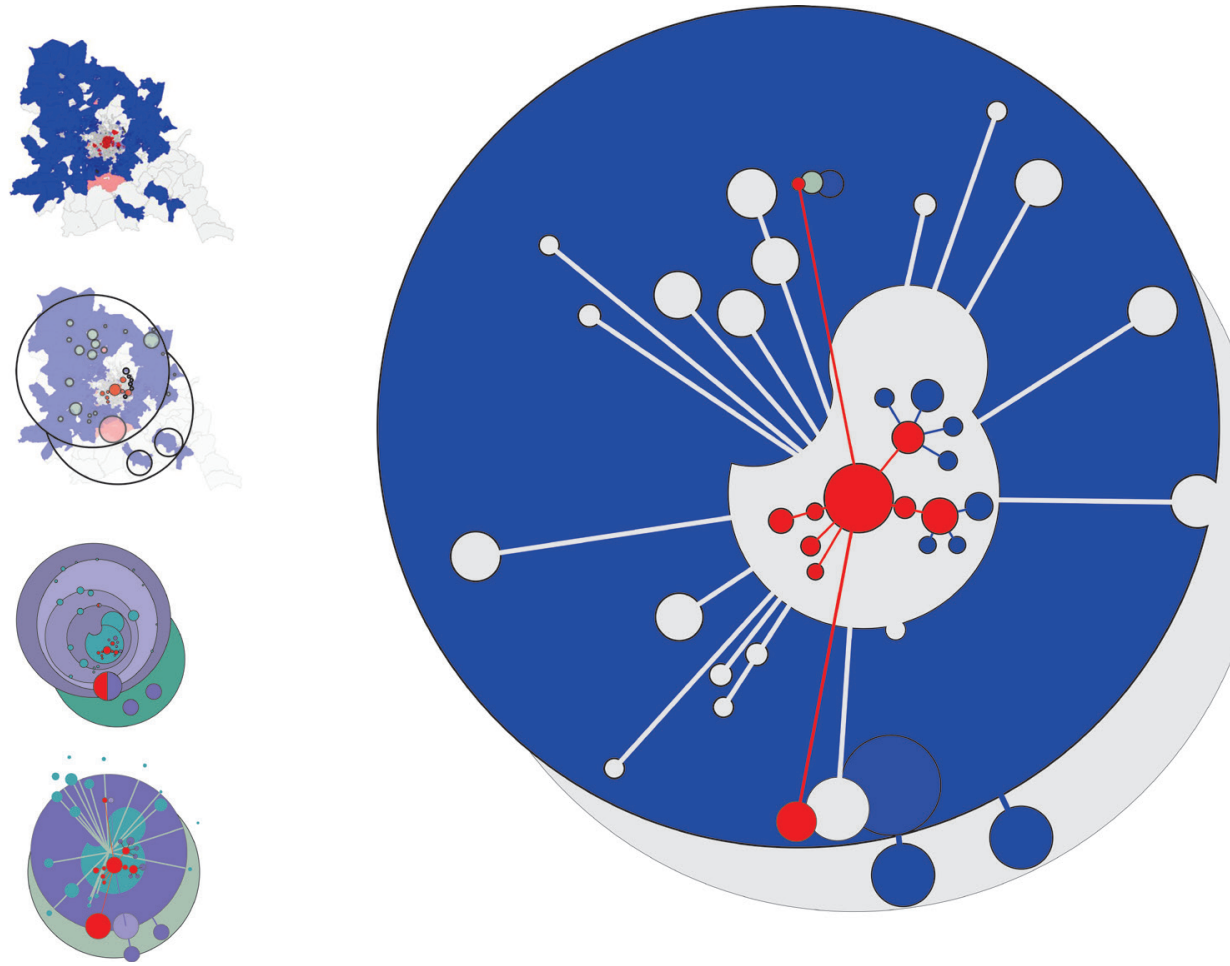

Fonte: Elaborado por Camilo Vladimir de Lima Amaral. 
Este diagrama síntese revela que existe uma estruturação espacial construindo uma série de relações, separações e integrações parciais de diferentes populações. Isso mantém uma funcionalidade de diferenciações sociais que são invisíveis se analisadas com indicadores agregados. Entretanto, ao se comparar a história de produção do espaço com as dinâmicas demográficas de setores censitários, foi possível abordar a complexidade lógica das estruturas de desigualdade presentes neste espaço urbano, que é hoje metropolitano.

Ao analisarmos com mais detalhes, percebemos também outro fator característico: o primeiro anel com índices sem significância estatística não possui uma forma perfeitamente circular (primeiro anel em cinza na Figura 4). Este anel é deformado, se estendendo para o nordeste da cidade de Goiânia. Tal configuração é mais evidente nos painéis A (rendimento), B (pessoas alfabetizadas) e C (pessoas de cor/raça branca) da Figura 3, com áreas em branco ao nordeste. Esta é a região que, desde a década de 1970, é protegida pelo planejamento por ser área de abastecimento da cidade. Além disso, é hoje submetida a uma Área de Proteção Ambiental que tem investido em programas para conscientização e atividades agrícolas sustentáveis, o que pode explicar a melhor situação dessa região (primeiro anel em cinza) em relação ao seu entorno (segundo anel em azul). Nesse sentido, é possível afirmar que a legislação ambiental não foi utilizada apenas como retórica, mas também contribuiu para uma maior justiça social nesta região.

Ainda é possível identificar uma aproximação da mancha do segundo anel de baixos índices se aproximando por noroeste, o que fica perceptível no painel A (rendimento) da Figura 3, com a área em azul escuro se aproximando mais do centro via noroeste. $\mathrm{Na}$ Figura 4, tal processo é ilustrado com a deformação côncava no noroeste do primeiro anel em cinza. Esta região é associada ao processo de invasões planejadas, que de alguma forma garantiram a posse da terra para populações mais pobres, que enfrentaram e ainda enfrentam disputas pela escritura da terra e estigma social.

\section{Considerações finais}

O estudo buscou integrar a interpretação do processo de produção do espaço com a efetiva estrutura de segregação espacial da RMG. A contextualização sobre produção do espaço urbano e planejamento de Goiânia, em conjunto com a ferramenta LISA de análise espacial de indicadores sociais, permitiu identificar como as dinâmicas sociais, econômicas e de gestão interagiram na formação da estrutura de segregação espacial da RMG. Esta análise possibilitou representar em um diagrama síntese (Figura 4) como a estrutura espacial de segregação “integrada e funcional” da RMG apresenta um espaço que não é homogêneo nem inclusivo. Ao contrário, a estrutura espacial de segregação da RMG mostra: a articulação de diferentes agrupamentos de setores censitários com padrões populacionais específicos; o estabelecimento de relações espaciais entre eles; a formação de um espaço desigual com padrões geométricos próprios; e uma funcionalidade espacial passível de ser analisada. 
A configuração do espaço da RMG não é de simples percepção no nível da experiência concreta da população, formando estruturas invisíveis de segregação. A análise diagramática permitiu visualizar que esta segregação funciona como um dispositivo espacial, reproduzindo condições de interdependência e reforçando as condições de vida enfrentadas no cotidiano pelos cidadãos. Esta ferramenta interpretativa permitiu identificar mecanismos e inter-relações de condições espaciais que não são uma simples centralidade ou uma pluricentralidade. Trata-se de diferentes tipos de centralidade funcionando integradamente e isoladamente, envoltos em diferentes massas contextuais na forma de anéis concêntricos.

Apesar de indicar a validade e importância da análise da estrutura da RMG, este estudo abre mais possibilidades de pesquisa. Quais fatores estariam influindo para o estabelecimento de populações com características distintas nas várias partes da RMG? Quais seriam as áreas de origem do novo contingente populacional na região? Seriam esses novos habitantes provenientes de outros Estados ou da própria RMG? Quais as principais características socioeconômicas da população nativa e dos migrantes da região? A mobilidade residencial estaria alterando a configuração socioespacial da RMG? Quais outras fontes de dados poderiam ajudar no esclarecimento destas questões, tais como valor da terra, infraestrutura, abastecimento de água, energia elétrica, esgotamento sanitário, coleta de lixo, movimentos pendulares, cultura e empregos?

Há a possibilidade de aprofundar o entendimento da estrutura de segregação da RMG com outros dados dos Censos Demográficos, disponibilizados pelo IBGE. Existem informações demográficas agregadas por setores censitários (questionário do universo) também para os Censos de 1991 e 2000, além de variáveis no nível individual que podem ser agregadas por áreas de ponderação (questionário da amostra) para os Censos de 1991, 2000 e 2010.

Os padrões de concentração da população da RMG podem ser analisados com técnicas dos Sistemas de Informações Geográficas (SIG). Por exemplo, regressões espaciais podem auxiliar na investigação de fatores associados com concentração populacional em determinadas áreas, tais como escolaridade, desemprego, ocupação, custos habitacionais, disponibilidade de transporte público e localização de centros de saúde e escolas. Nestes estudos multivariados, seria possível entender correlações de uma determinada variável dependente (por exemplo, rendimento) com uma série de variáveis independentes (tais como idade, escolaridade, cor/raça, ocupação, migração e fecundidade). Nesse caso, os dados provenientes dos questionários das amostras censitárias seriam de extrema importância, porque seria possível controlar a dinâmica metropolitana por um conjunto maior de variáveis. Modelos de regressão espaciais considerariam ainda as inter-relações de vizinhança existentes entre áreas de ponderação de residência.

É importante também analisar de que modo os deslocamentos populacionais inter-regionais e intrametropolitanos estão afetando a configuração socioespacial desta região. A estimação do nível e padrão dos fluxos migratórios para a RMG e dos movimentos populacionais entre seus municípios permitiria analisar a influência do espaço urbano e 
de fatores socioeconômicos e políticos sobre os fluxos populacionais. Além disso, esse estudo possibilitaria uma melhor compreensão da forma como tais fluxos afetam o espaço metropolitano. Pesquisas que investigam relações entre movimentos migratórios e políticas públicas são raras no país, as quais poderiam ser aplicáveis para outros contextos intranacionais.

Salienta-se a necessidade de desenvolver estudos que possam contribuir para a elaboração de uma proposta de reordenação do espaço urbano, no sentido de democratizar seu uso. Tais estudos de planejamento urbano e regional poderiam ser uma maneira de reforçar a discussão sobre o assunto, suscitando novos e mais amplos trabalhos sobre a RMG. $O$ intuito destas atividades seria elaborar recomendações para que políticas públicas efetivas sejam implementadas na região, considerando configurações e fatores associados com o processo de segregação espacial.

\section{Referências}

AMARAL, C. V. D. L. História dos bairros de Goiânia: uma visão interdisciplinar - o caso do setor universitário. Goiânia: UFG/UCG, Financiamento VPG, 2000.

AMARAL, E. F. D. L. Análise do nível, padrão e determinantes dos fluxos populacionais entre Bahia e São Paulo. Revista Brasileira de Estudos de População, v. 28, n. 2, p. 467-472, 2011.

ANSELIN, L. Local indicators of spatial association - LISA. Geographical Analysis, v. 27, n. 2, p. 93-115, 1995.

ANSELIN, L. Exploring spatial data with GeoDa: a workbook. Urbana, IL: Center for Spatially Integrated Social Science (CSISS), University of Illinois, 2005.

ANSELIN, L. Global spatial autocorrelation (1), Moran scatter plot and spatial correlogram. GeoDa: An Introduction to Spatial Data Analysis. The University of Chicago, 2018.

ANSELIN, L. Local spatial autocorrelation (1), univariate local statistics. GeoDa: An Introduction to Spatial Data Analysis. The University of Chicago, 2019.

ARANTES, C. M. D. F. Plano de Desenvolvimento Integrado de Goiânia. Goiânia: Instituto de Planejamento Municipal (Iplan), 1992.

ARANTES, G. D. F. Intervenções urbanas: rumo à cidade neoliberal. Curitiba: Editora Appris, 2015.

BOLAFFI, G. Habitação e urbanismo: o problema e o falso problema. In: MARICATO, E. (ed.). A produção capitalista da casa (e da cidade) no Brasil industrial. São Paulo: Editora Alfa-Omega, 1979. p. 37-70.

BONDUKI, N.; ROLNIK, R. Periferia da Grande São Paulo: reprodução do espaço como expediente de reprodução da força de trabalho. In: MARICATO, E. (ed.). A produção capitalista da casa (e da cidade) no Brasil industrial. São Paulo: Editora Alfa-Omega, 1979.

CAMPOS, F. I.; BERNARDES, G. D. A. Goiânia: sociabilidade na periferia. Ciências Humanas em Revista, v. 2, n. 1/2, p. 13-46, 1991.

CANCIAN, V.; VIDIGAL, V. C. G. A.; VIDIGAL, C. U. B. R. Pobreza de desigualdade de renda nos municípios da região Sul do Brasil: uma análise espacial. Maringá: Universidade Estadual de Maringá (UEM), Universidade Estadual do Paraná (Unespar), 2013. 
CHAVES, E. G. De invasor a posseiro: Estado-Igreja e a luta pela terra urbana. 1985. Dissertação (Mestrado) - Universidade Federal da Paraíba (UFPB), João Pessoa, 1985.

CHIARINI, T. Análise espacial da pobreza municipal no Ceará, 1991-2000. Revista de Economia, v. 34, n. 2, p. 69-93, 2008.

CHIARINI, T. Acesso a serviços públicos e pobreza no Rio Grande do Sul: uma análise espacial - 2000. Ensaios FEE, v. 30, n. 1, p. 195-228, 2009.

CUNHA, J. M. P. da; BAENINGER, R. (ed.). Redistribuição da população e meio ambiente: São Paulo e Centro-Oeste. Campinas: Núcleo de Estudos de População (Nepo), Universidade Estadual de Campinas (Unicamp), 1999.

CUNHA, J. M. P. da; JAKOB, A. A. E. Segregação socioespacial e inserção no mercado de trabalho na Região Metropolitana de Campinas. Revista Brasileira de Estudos de População, v. 27, n. 1, p. 115-139, 2010.

GONÇALVES, A. R. Goiânia: uma modernidade possível. Brasília: Ministério da Integração Nacional, 2003.

GRAEFF, E. A. Goiânia: 50 anos. Brasília: Ministério da Educação, Secretaria de Educação Superior (MEC-Sesu), 1985.

HARVEY, D. A produção capitalista do espaço. São Paulo: Annablume, 2005.

IPLAN - Instituto de Planejamento Municipal. Plano Diretor Integrado de Goiânia - PDIG 2000. Goiânia: Engevix \& Iplan, 1992.

LEFEBVRE, H. La production de l'espace. 3. ed. Paris: Editions Anthropos, 1986.

LEFEBVRE, H. A revolução urbana. Belo Horizonte: Editora UFMG, 1999.

LIMA, A. C. Plano diretor da cidade (Relatório apresentado ao Interventor Pedro Ludovico Teixeira); Goiânia - a nova capital (Resumo de um estudo). In: IBGE (ed.). Goiânia - Coletânea. Rio de Janeiro: Serviço Gráfico do Instituto Brasileiro de Geografia e Estatística (IBGE), 1942. p. 45-112.

MARCONATO, M.; BRAMBILLA, M. A.; RODRIGUES, K. C. T. T.; NASCIMENTO, S. P. D. Análise espacial da taxa de pobreza e da população rural da região Sul do país. Revista Textos de Economia, v. 18, n. 2, p. 16-40, 2015.

MENDONÇA, W. M.; RAMOS, P. D. S.; FRIAS, L. Uma análise espacial da dinâmica da desigualdade de renda em Minas Gerais em 1991, 2000 e 2010. Caderno de Estudos Interdisciplinares (CEI), edição especial - III Congresso ICSA - VIII Semana PIEPEX, p. 21-38, 2018.

MENHEM, N. L. A. F.; AMARAL, E. F. D. L. Vulnerabilidade no espaço urbano: análise da Região Metropolitana de Belo Horizonte, 2000. In: AMARAL, E. F. D. L. et al. (ed.). Aplicações de técnicas avançadas de avaliação de políticas públicas. Belo Horizonte: Fino Traço, 2014.

MOYSÉS, A. Desigualdades sócio-espaciais no Centro-Oeste brasileiro: o caso da Região Metropolitana de Goiânia. In: VIII CONGRESSO LUSO-AFRO-BRASILEIRO DE CIÊNCIAS SOCIAIS, 2004, Coimbra. Anais [...]. Coimbra: Centro de Estudos Sociais (CES), Universidade de Coimbra, 2004.

MOYSÉS, A. Análise das regiões metropolitanas do Brasil: como anda a metrópole goianiense. Goiânia: Observatório das Metrópoles, 2005.

MOYSÉS, A.; BERNARDES, G. D. A. Segregação urbana e desigualdade social em Goiânia: Estado, mercado imobiliário e dinâmica socioespacial. In: MOYSÉS, A. (ed.). Cidade, segregação urbana e planejamento. Goiânia: Editora UCG, 2005. p. 173-204. 
NUNES, F. G. Análise exploratória espacial de indicadores de desenvolvimento socioambiental das regiões de planejamento do norte e nordeste goiano. Ateliê Geográfico, v. 7, n. 1, p. 237-259, 2013.

OLIVEIRA, A. M. V. D. Plano Diretor de Goiânia: Luis Saia. 1985. Monografia (Conclusão do Ramo de Teoria e História da Arquitetura do Curso de Arquitetura) - Universidade Católica de Goiás (UCG), Goiânia, 1985.

PEROBELLI, F. S.; HADDAD, E. A. Padrões de comércio interestadual no Brasil, 1985 e 1997. Revista de Economia Contemporânea, v. 10, n. 1, p. 61-88, 2006.

RIBEIRO, L. C. D. Q.; RIBEIRO, M. G. (ed.). Metrópoles brasileiras: síntese da transformação na ordem urbana 1980 a 2010. Rio de Janeiro: Letra Capital, Observatório das Metrópoles, 2018.

RIGOTTI, J. I. R.; VASCONCELLOS, I. R. P. Uma análise espacial exploratória dos fluxos populacionais brasileiros nos períodos 1986-1991 e 1995-2000. In: ENCONTRO NACIONAL SOBRE MIGRAÇÕES, 4., 2005. Anais [...]. Rio de Janeiro: Abep, 2005.

SAIA, L. Plano Diretor de Goiânia. Goiânia, 1962.

SANTOS, E. I. D.; CARVALHO, I. C. C. L. S. D.; BARRETO, R. C. A. S. Análise espacial da pobreza no Nordeste brasileiro: uma aplicação do IMP. In: XI ENCONTRO DE ECONOMIA BAIANA, 2015. Anais [...]. Salvador, 2015. p. 252-276.

SANTOS, E. I. D.; CARVALHO, I. C. C. L. S. D.; BARRETO, R. C. A. S. Pobreza multidimensional no estado da Bahia: uma análise espacial a partir dos censos de 2000 e 2010. Revista de Administração Pública, v. 51, n. 2, p. 240-263, 2017.

SANTOS, M. O espaço dividido: os dois circuitos da economia urbana dos países subdesenvolvidos. Rio de Janeiro: F. Alvez, 1979.

SANTOS, M. A urbanização brasileira. 3. ed. São Paulo: Hucitec, 1996.

SILVA, G. J. C. D.; SOUZA, E. C.; MARTINS, H. E. D. P. Produção agropecuária em municípios de Minas Gerais (1996-2006): padrões de distribuição, especialização e associação espacial. Revista de Economia e Sociologia Rural, v. 50, n. 2, p. 333-350, 2012.

SILVEIRA, G. F. et al. Análise espacial da pobreza nos municípios do Estado de São Paulo. Revista de Economia e Administração, v. 9, n. 2, p. 207-225, 2010.

SOJA, E. Postmetropolis: critical studies of cities and regions. Oxford: Backwell, 2000.

UN-HABITAT. State of the world's cities 2008/2009: harmonious cities. Nairobi: United Nations Human Settelments Programme (UN-Habitat), 2008.

UN-HABITAT. State of the world's cities 2010/2011: bridging the urban divide. Nairobi: United Nations Human Settelments Programme (UN-Habitat), 2010.

UN-HABITAT. World cities report 2016: urbanization and development, emerging cities. Nairobi: United Nations Human Settelments Programme (UN-Habitat), 2016.

\section{Sobre os autores}

Ernesto Friedrich de Lima Amaral é PhD em Sociologia/Demografia pela The University of Texas at Austin, mestre em Demografia pela Universidade Federal de Minas Gerais (UFMG) e graduado em Ciências Sociais pela Universidade Federal de Goiás (UFG). Professor assistente na Texas A\&M University. 
Camilo Vladimir de Lima Amaral é PhD em Arquitetura pela University of East London, mestre em Arquitetura e Urbanismo pela Universidade Federal de Minas Gerais (UFMG) e graduado em Arquitetura e Urbanismo pela Pontifícia Universidade Católica de Goiás (PUC Goiás). Professor adjunto na Universidade Federal de Goiás.

\title{
Endereço para correspondência
}

\author{
Ernesto Friedrich de Lima Amaral \\ Texas A\&M University, Department of Sociology \\ 311 Academic Building, College Station \\ TX 77843-4351, Estados Unidos \\ Camilo Vladimir de Lima Amaral \\ Universidade Federal de Goiás (UFG), Faculdade de Artes Visuais (FAV) \\ Avenida Esperança, sala 21, campus Samambaia \\ 74690900 - Goiânia-GO, Brasil
}

\begin{abstract}
Invisible Structures of Segregation in the Metropolitan Region of Goiânia
\end{abstract}

This article aims to research the invisible structure of segregation of the Metropolitan Region of Goiânia (RMG), through the interrelations among processes of urban space production, urban planning principles, and population dynamics. These interrelations are fundamental to understanding the structure of socioeconomic inequalities in metropolitan areas. We analyzed the process of formation of segregation structure in the region, addressing the various urban plans developed for Goiânia. We provide a brief analysis of population indicators based on Demographic Census data from 1950 to 2010 and local indicators of spatial association in 2010 to characterize different dynamics in the region. We developed a critical analysis of these aspects, in order to identify and illustrate the main characteristics of the formation of this region in a summary diagram. We discussed how this overall spatial structure contributes to the reproduction of segregated social relations. Main results indicate that RMG does not have a simple centrality or a multi-centrality. There are a series of concentric rings with different types of centralities, which function in an integrated - but not inclusive - segregation system. We also identify research topics of social, demographic, and economic dynamics that would improve our understanding of spatial formation and urban planning in this region.

Keywords: Metropolitan Region of Goiânia. Urban space. Segregation. Urban planning. History. Demography. Indicators. Brazil.

\section{Resumen}

Estructuras invisibles de segregación en la Región Metropolitana de Goiânia

Este artículo busca investigar la estructura invisible de segregación de la Región Metropolitana de Goiânia (RMG) a partir de las interrelaciones entre procesos de producción del espacio urbano, principios de planificación y dinámicas poblacionales. Estas interrelaciones son fundamentales para comprender la estructuración de desigualdades socioeconómicas en las 
áreas metropolitanas. Analizamos el proceso de formación de la estructura de segregación en la región, abordando los diversos planos urbanísticos desarrollados para Goiânia. Disponibilizamos un breve análisis de indicadores poblacionales basados en datos de los censos demográficos desde 1950 hasta 2010 y de indicadores locales de asociación espacial en 2010 para caracterizar las diferentes dinámicas de la región. Desarrollamos un análisis crítico de estos aspectos con el fin de identificar y mostrar las principales características de la formación de esta región en un diagrama de síntesis. Buscamos discutir cómo esta estructura espacial resultante contribuye a la reproducción de relaciones sociales segregadas. Los principales resultados indican que la RMG no tiene una simple centralidad o una multicentralidad, sino que hay en ella una serie de anillos concéntricos con diferentes tipos de centralidad que funcionan en un sistema integrado, pero no inclusivo, de segregación. Identificamos también temas de investigación para analizar dinámicas sociales, demográficas y económicas que permiten aumentar el entendimiento de la formación espacial y de planificación urbana de esa región.

Palabras clave: Región Metropolitana de Goiânia. Espacio urbano. Segregación. Planificación urbana. Historia. Demografía. Indicadores. Brasil. 


\section{Apêndice A}

\section{QUADRO A1}

Planejamento, dinâmica demográfica e (re)produção do espaço em Goiânia no contexto brasileiro 1933-2018

\begin{tabular}{|llll|}
\hline Período & Planejamento & Dinâmica demográfica & (Re)produção do espaço \\
\hline 1933-1945 & Modelo ideal & $\begin{array}{l}\text { Incentivo ao crescimento } \\
\text { populacional lento e contínuo }\end{array}$ & Estado Novo, modernização \\
\hline 1945-1964 & Desplanejamento & Rápido crescimento populacional & \begin{tabular}{l} 
Especulação, espraiamento \\
\hline 1964-1987
\end{tabular} \\
$\begin{array}{l}\text { Técnico-burocracia, } \\
\text { cooptação }\end{array}$ & $\begin{array}{l}\text { Rápido crescimento } \\
\text { populacional, seguido de } \\
\text { arrefecimento do crescimento } \\
\text { populacional }\end{array}$ & $\begin{array}{l}\text { Concentração, mercantilização, } \\
\text { invasões, contrastes }\end{array}$ \\
\hline 1988-2000 & $\begin{array}{l}\text { Compreensivo no centro, } \\
\text { desplanejamento nas } \\
\text { bordas }\end{array}$ & $\begin{array}{l}\text { Crescimento populacional nas } \\
\text { cidades do entorno }\end{array}$ & Reinvenção da segregação \\
\hline 2000-2018 & Parcerias público-privadas & $\begin{array}{l}\text { Crescimento populacional no } \\
\text { centro e nas cidades do entorno }\end{array}$ & $\begin{array}{l}\text { Intensificação das diferenças, } \\
\text { competição entre cidades }\end{array}$ \\
\hline
\end{tabular}

Fonte: Elaborado por Camilo Vladimir de Lima Amaral.

\section{QUADRO A2}

Variáveis selecionadas dos resultados do universo do Censo Demográfico de 2010, agregados por setores censitários

\begin{tabular}{|c|c|c|}
\hline Indicador & Numerador & Denominador \\
\hline $\begin{array}{l}\text { Figuras } 3 \text { e A1: } \\
\text { Rendimento médio } \\
\text { domiciliar per capita }\end{array}$ & $\begin{array}{l}\text { Arquivo renda dos domicílios } \\
\text { (DomicílioRenda_GO.csv) } \\
\text { V003: Total do rendimento nominal } \\
\text { mensal dos domicílios particulares } \\
\text { permanentes }\end{array}$ & $\begin{array}{l}\text { Arquivo básico (Básico_GO.csv) } \\
\text { V002: Moradores em domicílios } \\
\text { particulares permanentes ou população } \\
\text { residente em domicílios particulares } \\
\text { permanentes }\end{array}$ \\
\hline $\begin{array}{l}\text { Figuras } 3 \text { e A1: } \\
\text { Percentual de pessoas } \\
\text { alfabetizadas }\end{array}$ & $\begin{array}{l}\text { Arquivo alfabetização, total (Pessoa01_ } \\
\text { GO.csv) } \\
\text { V001: Pessoas alfabetizadas com } 5 \text { ou } \\
\text { mais anos de idade }\end{array}$ & $\begin{array}{l}\text { Arquivo idade, total (Pessoa13_GO.csv) } \\
\text { V001: Pessoas residentes em domicílios } \\
\text { particulares e domicílios coletivos } \\
\text { Subtraído de: } \\
\text { V022: Pessoas com menos de } 1 \text { ano de } \\
\text { idade } \\
\text { V035: Pessoas de } 1 \text { ano de idade } \\
\text { V036: Pessoas com } 2 \text { anos de idade } \\
\text { V037: Pessoas com } 3 \text { anos de idade } \\
\text { V038: Pessoas com } 4 \text { anos de idade }\end{array}$ \\
\hline $\begin{array}{l}\text { Figuras } 3 \text { e A1: } \\
\text { Percentual de pessoas } \\
\text { de cor/raça branca }\end{array}$ & $\begin{array}{l}\text { Arquivo cor ou raça, idade e gênero } \\
\text { (Pessoa03_GO.csv) } \\
\text { V002: Pessoas residentes e cor ou raça } \\
\text { - branca }\end{array}$ & $\begin{array}{l}\text { Arquivo cor ou raça, idade e gênero } \\
\text { (Pessoa03_GO.csv) } \\
\text { V001: Pessoas residentes }\end{array}$ \\
\hline $\begin{array}{l}\text { Figuras } 3 \text { e A1: } \\
\text { Percentual de } \\
\text { domicílios com } \\
\text { abastecimento da } \\
\text { rede geral de água }\end{array}$ & $\begin{array}{l}\text { Arquivo domicílio, características gerais } \\
\text { (Domicilio01_GO.csv) } \\
\text { V106: Domicílios particulares } \\
\text { permanentes do tipo casa com } \\
\text { abastecimento de água da rede geral } \\
\text { V145: Domicílios particulares } \\
\text { permanentes do tipo casa de vila ou em } \\
\text { condomínio com abastecimento de água } \\
\text { da rede geral } \\
\text { V184: Domicílios particulares } \\
\text { permanentes do tipo apartamento com } \\
\text { abastecimento de água da rede geral }\end{array}$ & $\begin{array}{l}\text { Arquivo domicílio, características gerais } \\
\text { (Domicilio01_GO.csv) } \\
\text { V002: Domicílios particulares } \\
\text { permanentes }\end{array}$ \\
\hline
\end{tabular}




\begin{tabular}{|c|c|c|}
\hline Indicador & Numerador & Denominador \\
\hline $\begin{array}{l}\text { Figura A2: Percentual } \\
\text { de domicílios com lixo } \\
\text { coletado }\end{array}$ & $\begin{array}{l}\text { Arquivo domicílio, características gerais } \\
\text { (Domicilio01_GO.csv) } \\
\text { V035: Domicílios particulares } \\
\text { permanentes com lixo coletado }\end{array}$ & $\begin{array}{l}\text { Arquivo domicílio, características gerais } \\
\text { (Domicilio01_GO.csv) } \\
\text { V002: Domicílios particulares } \\
\text { permanentes }\end{array}$ \\
\hline $\begin{array}{l}\text { Figura A2: Percentual } \\
\text { de domicílios } \\
\text { com banheiro e } \\
\text { esgotamento sanitário } \\
\text { via rede geral de } \\
\text { esgoto ou pluvial }\end{array}$ & $\begin{array}{l}\text { Arquivo domicílio, características gerais } \\
\text { (Domicilio01_GO.csv) } \\
\text { v017: Domicílios particulares } \\
\text { permanentes com banheiro de uso } \\
\text { exclusivo dos moradores ou sanitário e } \\
\text { esgotamento sanitário via rede geral de } \\
\text { esgoto ou pluvial }\end{array}$ & $\begin{array}{l}\text { Arquivo domicílio, características gerais } \\
\text { (Domicilio01_GO.csv) } \\
\text { V002: Domicílios particulares } \\
\text { permanentes }\end{array}$ \\
\hline
\end{tabular}

Fonte: Censo Demográfico do Brasil de 2010. Disponível em: 〈ftp://ftp.ibge.gov.br/Censos/Censo_Demografico_2010/ Resultados_do_Universo/Agregados_por_Setores_Censitarios/GO_20171016.zip〉.

\section{FIGURA A1}

Distribuição espacial de variáveis socioeconômicas, demográficas e de infraestrutura nos setores censitários da Região Metropolitana de Goiânia - 2010

A. Rendimento médio domiciliar per capita

Quantil: Rendimento per capita

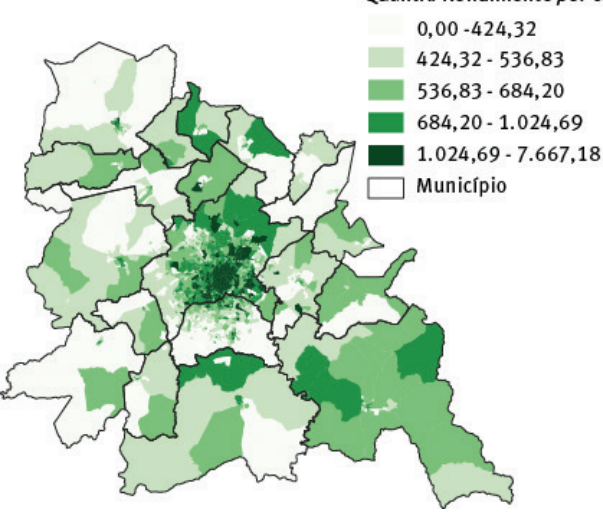

C. Percentual de pessoas de cor/raça branca

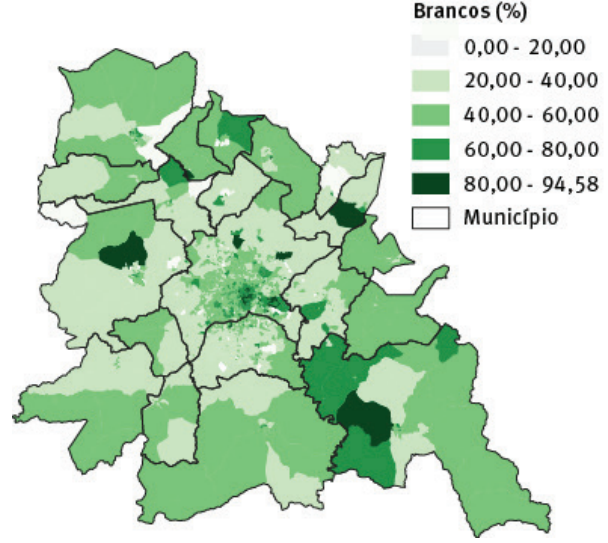

Fonte: Censo Demográfico do Brasil de 2010.

\section{B. Percentual de pessoas alfabetizadas}

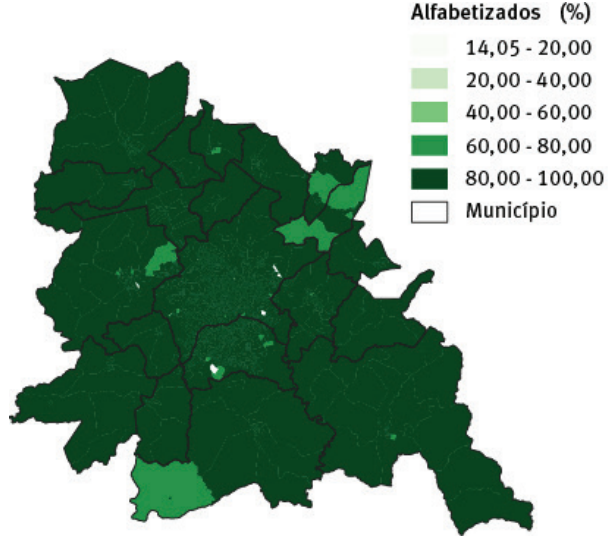

D. Percentual de domicílios com rede geral de água

Rede geral de água (\%)

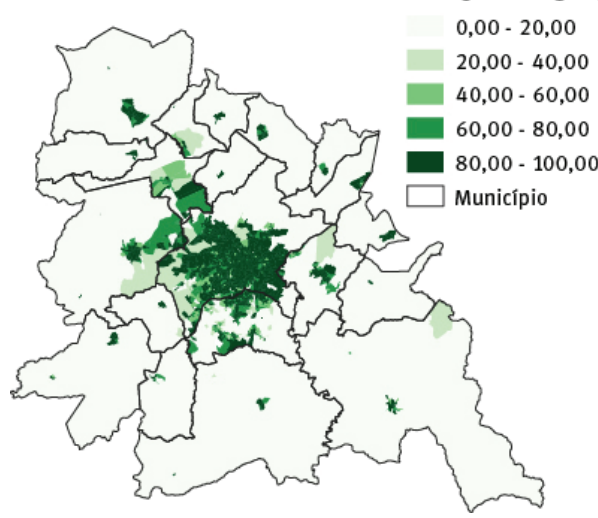




\section{FIGURA A2}

Distribuição espacial e agrupamentos de indicadores locais de associação espacial (LISA) do percentual de domicílios com lixo coletado e com rede geral de esgoto nos setores censitários da Região Metropolitana de Goiânia - 2010

A. Percentual de domicílios com lixo coletado

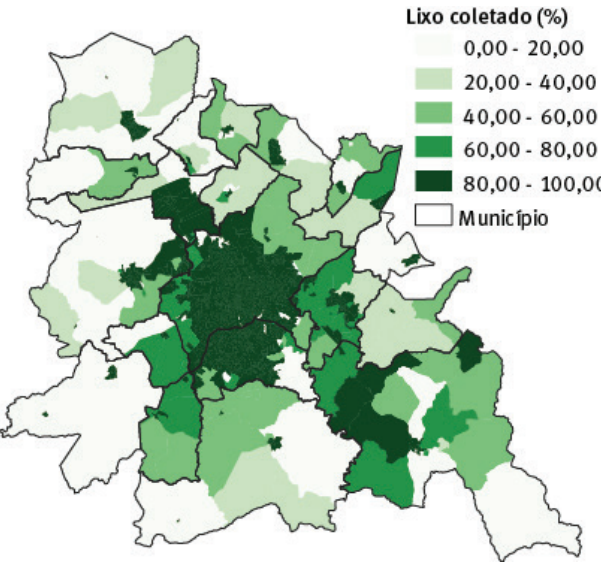

C. Percentual de domicílios com lixo coletado I de Moran: 0,4751 (pseudo p-valor: 0,001)

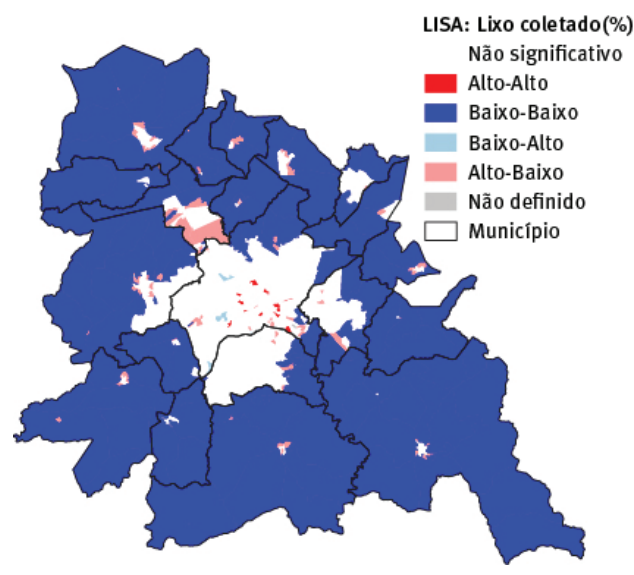

Fonte: Censo Demográfico do Brasil de 2010.
B. Percentual de domicílios com rede geral de esgoto

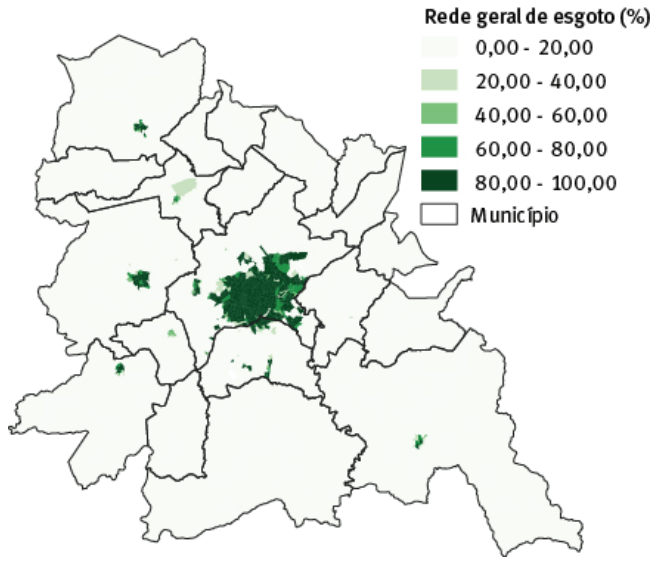

D. Percentual de domicílios com rede geral de esgoto I de Moran: 0,8726 (pseudo p-valor: 0,001)

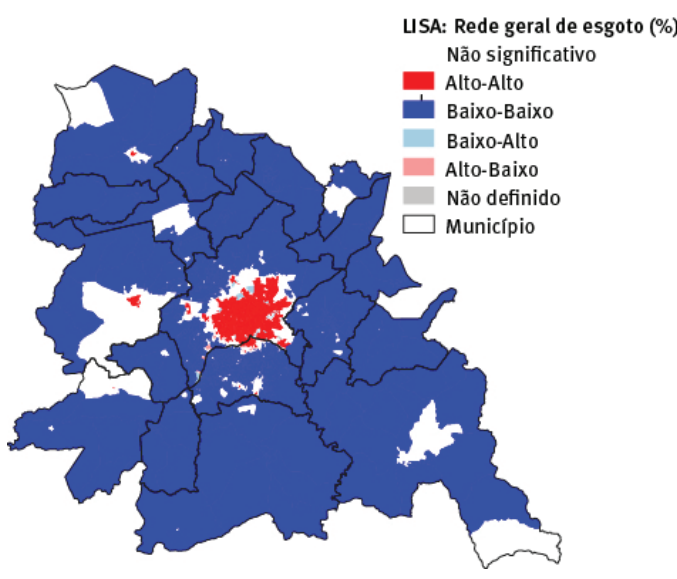

Recebido para publicação em 09/04/2019 Aceito para publicação em 27/09/2019 